García-Pérez, T., Ferreira, A. M. G., Yáñez, G., Iturrieta, P. C., Cembrano, J. (2021): Effects of topography and basins on seismic wave amplification: the Northern Chile coastal cliff and intramountainous basins. - Geophysical Journal International, 227, 2, 1143-1167.

https://doi.org/10.1093/gji/ggab259 


\title{
Effects of topography and basins on seismic wave amplification: the Northern Chile coastal cliff and intramountainous basins
}

\author{
Tiaren García-Pérez, ${ }^{1}$ Ana M.G. Ferreira, ${ }^{2,3}$ Gonzalo Yáñez, ${ }^{1,4}$ Pablo Iturrieta ${ }^{5,6}$ and \\ José Cembrano ${ }^{1,7}$ \\ ${ }^{1}$ Departamento de Ingeniería Estructural y Geotécnica, Pontificia Universidad Católica de Chile, Vicuña Mackenna 4860, Macul, Santiago, 7820244, Chile. \\ E-mail: trgarcia@uc.cl \\ ${ }^{2}$ CERIS, Instituto Superior Técnico, Universidade de Lisboa, Av. Rovisco Pais 1, 1049-001 Lisboa, Portugal \\ ${ }^{3}$ Department of Earth Sciences, Faculty of Mathematical \& Physical Sciences, University College London, London WC1E 6BT, UK \\ ${ }^{4}$ Millenium Nucleus for Metal Tracing Along Subduction, Universidad de Chile, Santiago, Casilla 13518, Correo 21, Chile \\ ${ }^{5}$ Helmholtz Centre Potsdam, GFZ German Research Centre for Geoscience, Potsdam, Telegrafenberg, 14473, Germany \\ ${ }^{6}$ Institute of Geoscience, University of Potsdam, Karl-Liebknecht-Strasse 24-25, 14414 Potsdam, Germany \\ ${ }^{7}$ Andean Geothermal Center of Excellence (CEGA, FONDAP-CONICYT), Santiago, Casilla 13518, Correo 21, Chile
}

\begin{abstract}
SUMMAR Y
During earthquakes, structural damage is often related to soil conditions. Following the 2014 April $1 M_{\mathrm{w}} 8.1$ Iquique earthquake in Northern Chile, damage to infrastructure was reported in the cities of Iquique and Alto Hospicio. In this study, we investigate the causes of site amplification in the region by numerically analysing the effects of topography and basins on observed waveforms in the frequency range $0.1-3.5 \mathrm{~Hz}$ using the spectral element method. We show that topography produces changes in the amplitude of the seismic waves (amplification factors up to 2.2 in the frequency range $0.1-3.5 \mathrm{~Hz}$ ) recorded by stations located in steep areas such as the $c a$. 1-km-high coastal scarp, a remarkable geomorphological feature that runs north-south, that is parallel to the coast and the trench. The modelling also shows that secondary waves - probably related to reflections from the coastal scarp - propagate inland and offshore, augmenting the duration of the ground motion and the energy of the waveforms by up to a factor of three. Additionally, we find that, as expected, basins have a considerable effect on ground motion amplification at stations located within basins and in the surrounding areas. This can be attributed to the generation of multiple reflected waves in the basins, which increase both the amplitude and the duration of the ground motion, with an amplification factor of up to 3.9 for frequencies between 1.0 and $2.0 \mathrm{~Hz}$. Comparisons between real and synthetic seismic waveforms accounting for the effects of topography and of basins show a good agreement in the frequency range between 0.1 and $0.5 \mathrm{~Hz}$. However, for higher frequencies, the fit progressively deteriorates, especially for stations located in or near to areas of steep topography, basin areas, or sites with superficial soft sediments. The poor data misfit at high frequencies is most likely due to the effects of shallow, small-scale 3-D velocity heterogeneity, which is not yet resolved in seismic images of our study region.
\end{abstract}

Key words: Numerical modelling; Earthquake hazards; Site effects; Wave propagation.

\section{INTRODUCTION}

Site effects due to earthquakes are widely studied as they often lead to casualties and structural damage in populated cities. In the last decades, significant efforts have been made to evaluate site effects through experimental, analytical and numerical methods (e.g. Geli et al. 1988; Aki 1993; Sánchez-Sesma et al. 2002; Álvarez-Rubio et al. 2004; Ghofrani et al. 2013; Barani et al. 2014; Massa et al. 2014; Kuo et al. 2018; Wang et al. 2018). Several studies have shown that records of severe damage and strong ground motion can match seismic amplification zones near the top and/or the slopes of topographic irregularities (e.g. Celebi 1987; Buech et al. 2010; Hough et al. 2010; Massa et al. 2010; Barani et al. 2014; Burjánek et al. 2014) or within sedimentary basins (e.g. Celebi 1987; Singh et al. 1988; Campillo et al. 1989; Faccioli 1991; Borcherdt \& Glassmoyer 1992; Bouckovalas \& Kouretzis 2001; Buech et al. 2010; Hough et al. 2010; Massa et al. 2010; Miksat et al. 2010; Burjánek et al. 2014; Meza-Fajardo et al. 2016). In general, these studies observed 
amplifications in seismic waves whose wavelengths are comparable to the width of mountains and the thickness of basins, and also observed strong frequency dependency in the degree of amplification. Early analytical studies focused on the incidence of plane waves on simple layered features, such as semicircular, triangle or rectangular valleys and hills, or simple layered step structures. These studies found that topographic and geological features can have significant frequency-dependent effects on seismic waves, ranging from amplification to de-amplification at given sites (Bouchon 1973; Geli et al. 1988; Faccioli 1991; Sánchez-Sesma et al. 1993; Pedersen et al. 1994; Ashford et al. 1997). However, the analytical calculations performed in these studies typically do not reproduce the full complexity of real data. This led researchers to turn their attention to the implementation of advanced numerical modelling techniques, which have been made possible thanks to advances in computational power (e.g. Bouchon et al. 1996; Komatitsch \& Vilotte 1998; Paolucci 2002; Álvarez-Rubio et al. 2004; Paolucci \& Morstabilini 2006; Lee et al. 2009; Miksat et al. 2010; Fan et al. 2014; Restrepo et al. 2016). In particular, in the last $20 \mathrm{yr}$, the spectral element method (SEM) has been widely and successfully implemented to simulate seismic wave propagation in 3-D earth models. The SEM is a highly accurate technique which allows to account for complex topographic surfaces, internal discontinuities and sedimentary basin features (e.g. Komatitsch \& Tromp 1999; Komatitsch et al. 2004, 2010; Lee et al. 2009). However, despite several studies investigating the effects of topography and complex geology on seismic waves, the poor knowledge of the geometry and mechanical properties of subsoil materials and a lack of validations with real data still limit the understanding of the site effects.

In recent decades, the instrumental seismic coverage of Northern Chile has substantially improved, with an expansion of both permanent and temporary seismic networks, including broad-band seismic stations as well as accelerometers (Barrientos 2018). Therefore, high-quality seismic data are available for the 2014 April $1 M_{\mathrm{w}}$ 8.1 Iquique earthquake in Northern Chile, as well as for its foreshocks and aftershocks, which provides an excellent opportunity to investigate the causes of the site effects, and notably the interaction between topography, soil properties and seismic waves.

The 2014 April $1 M_{\mathrm{w}} 8.1$ Iquique earthquake was a megathrust event produced by subduction of the Nazca plate beneath South American plate, and its epicentre was located in the widely known Northern Chile seismic gap (Fig. 1). The Northern Chile seismic gap is located in the area between $19^{\circ} \mathrm{S}$ and $23^{\circ} \mathrm{S}$, within a wider area where the last two major earthquakes occurred in 1868 (approximately between $16^{\circ}$ and $19^{\circ}$ ) and 1877 (approximately between $19^{\circ}$ and $22^{\circ}$ ), both of which had magnitudes of $M_{\mathrm{w}} 8.8$ (Comte \& Pardo 1991). Nevertheless the large magnitude of the 2014 Iquique earthquake, the potential for a large event in this region still remains, given that over 70 per cent of the length of the Northern Chile seismic gap has not been released, as shown in Fig. 1 (Bürgmann 2014; Hayes et al. 2014; Lay et al. 2014; Ruiz et al. 2014). Additionally, the Northern Chile region presents notable geomorphological features in the emerged forearc due to the combined effect of a hyperarid climate and plate convergence. These features include several intra-mountainous basins deposited in the coastal cordillera, and a steeply sloping coastal cliff with an average height of 1000 meters (Fig. 1) whose origin is not entirely understood (Paskoff 1978; Marquardt et al. 2004; Tolorza et al. 2009; Martinod et al. 2016). The Iquique earthquake produced peak shaking intensities of VI to VIII on land and ground accelerations of 73.45 per cent (Cilia et al. 2017; Hayes et al. 2017), in addition a $2 \mathrm{~m}$ maximum high tsunami hit coastal towns from southern Peru to northern Chile. At least 13000 houses and buildings were damaged or destroyed, which were mostly located close to the coastal cliff and soft soils areas, and thus the damage was attributed to site effects due the region's geomorphological features (Hayes et al. 2014; Becerra et al. 2015, 2016). More generally, given that northern Chile is prone to large earthquakes, understanding the effect of its prominent topographic features and basins on seismic waveforms is the key to interpreting spatial variation of seismic shaking in the region.

In this study, we investigate the potential causes of these site effects by simulating seismic wave propagation in Northern Chile using the spectral element method and, for the first time, the effects of topography and sedimentary basins on waveforms recorded in Northern Chile are study by the comparison of the simulated waveforms with observations. In order to reduce potential source effects we use two small-moderate magnitude events with magnitudes $M_{\mathrm{w}}$ 4.5 and 5.4 that occurred as part of the 2014 Iquique earthquake sequence. This allows us to discuss the likely causes of observed amplifications in the region during the 2014 Iquique earthquake, as well as general implications of our results.

\section{GEOLOGICAL FRAMEWORK}

As shown in Fig. 1, the main geomorphological features of the emerged forearc from $18^{\circ} \mathrm{S}$ to $25^{\circ} \mathrm{S}$ in the study region are, from west to east, the coastal plains, the coastal cliff, the coastal cordillera and the central depression. The coastal plains are a series of narrow (less than $3 \mathrm{~km}$ wide) marine abrasion surfaces that are limited to the east by the 0.5-2-km high coastal cliff (Paskoff 1978; Marquardt et al. 2004, 2008; Tolorza et al. 2009; Quezada et al. 2010). Iquique is located in a $3-\mathrm{km}$ wide coastal plain, where stratified rocks are covered by thin layers of marine, colluvial and aeolian deposits. The coastal cordillera is made up of Jurassic-Cretaceous volcanic arc rocks with an average width of about $30 \mathrm{~km}$ and a height of between 1000 and $2000 \mathrm{~m}$ a.s.1. (González et al. 2003; Veiga et al. 2004; Cembrano et al. 2005; Allmendinger \& González 2010; Quezada et al. 2010). Several intramountainous basins produced by crustal faulting and filled by sedimentary deposits are located within the coastal cordillera. In the following paragraphs we describe the most relevant basins for the purpose of the present study, Alto Hospicio and Pampa del Tamarugal. Alto Hospicio is an NS-elongated basin, which has an average length of $\sim 8 \mathrm{~km}$, an average width of $\sim 2 \mathrm{~km}$, and is located at an average height of $\sim 500 \mathrm{~m}$ a.s.l. This basin has a sharp near-vertical boundary next to the coast cliff associated with normal faulting processes and has maximum depth of 200-350 m (Marquardt et al. 2008; García-Pérez et al. 2018). This basin is one of the few intra-mountain basins that intersects the coastal cliff, and contains Alto Hospicio city, with a population of $\sim 100000$. On the other hand, the Pampa del Tamarugal basin is located in the central depression at a distance of approximately $25 \mathrm{~km}$ from the coastline. This basin, located in the central depression, covers a surface of approximately $300 \times 75 \mathrm{~km}^{2}$. Similar to the Alto Hospicio basin, its western boundary is quite sharp, being associated with a half-graben produced by normal faults during the Mesozoic that reactivate as reverse faults during contraction deformation in the Cenozoic (Galli Olivier \& Dingman 1962; Muñoz \& Charrier 1996; Mpodozis \& Ramos 2008; Bascuñán et al. 2016). The basin's northern part is filled by approximately $1000 \mathrm{~m}$ of continental deposits and pyroclastic flows, with the towns of Huara and Pozo Almonte being located in its western border (Nester \& Jordan 2012; Fuentes et al. 2017). The electromagnetic transient TEM geophysical study carried out in the northern part of the Pampa 


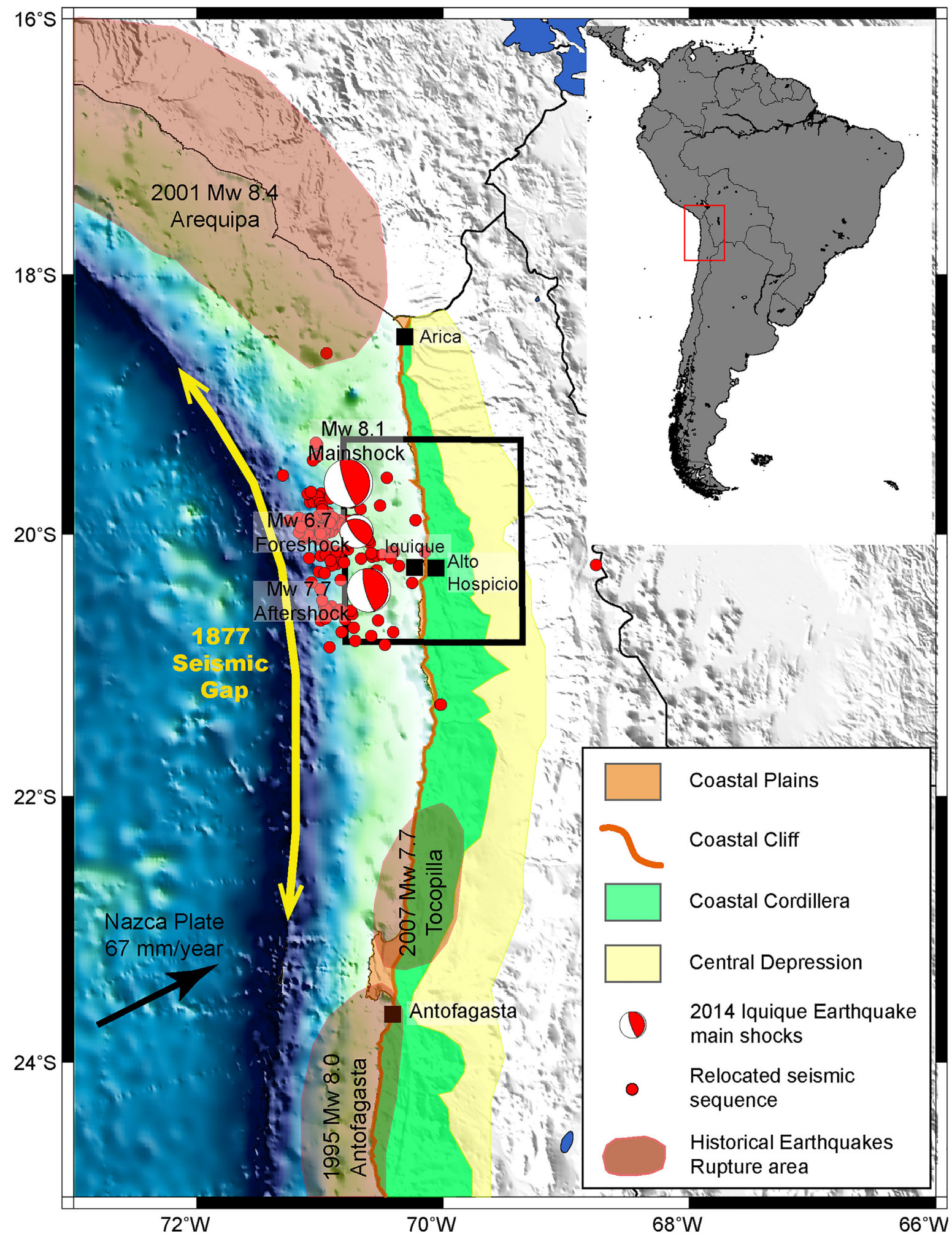

Figure 1. Topographic map of Northern Chile showing the Iquique earthquake sequence and the main geomorphological units of the emerged forearc. The red beach balls represent the focal mechanisms of the foreshock, main shock and the main aftershock events, as obtained from the Global CMT catalogue (Dziewonski et al. 1981 ). The red dots are the relocated seismicity from March to July 2014 as obtained from León-Ríos et al. (2016). The black rectangle shows the study area. Dark red shaded polygons represent rupture areas of historical earthquakes. Other elements are described in the inlet legend. 
del Tamarugal basin agrees with the stratigraphic studies, finding basin thickness between 1000 and $1160 \mathrm{~m}$ (Viguier et al. 2018). On the other hand, the southern part of the Pampa del Tamarugal basin is shallower $(\sim 300 \mathrm{~m})$, it is geologically more complex than its northern counterpart (Fig. 2), and its internal structure is poorly constrained, lacking geophysical information in a wide area. Hence, in this study we focus on the simpler and better constrained northern part of the Tamarugal basin.

The geological map in Fig. 2 shows the main geological units in the study area. In the coastal cordillera some Jurassic and Cretaceous marine volcano sedimentary rocks are intruded by CretaceousJurassic rocks, composed by diorite, granodiorite and granite (Sernageomin 2003; Marquardt et al. 2008; Vásquez \& Sepúlveda 2013; López et al. 2017). Above the Jurassic and Cretaceous rocks, Cenozoic sediments are deposited in the coastal plains, the intramountainous basins within the coastal cordillera, and in the Pampa del Tamarugal basin, in the central depression. Fig. 2 also shows the locations of the seismic stations used in this study (coordinates are given in Table 1), which are located over different soil units. As shown in the Fig. 2, stations PSGCX and PATCX are located in the coastal cordillera above volcanic rocks; however the station PATCX is located closer to the coastal cliff. Stations T01A, T03A, T05A and T06A are located in the coastal plain. The stations T01A and T03A are located above aeolian deposits and stations T05A and T06A are located above Jurassic — Cretaceous sedimentary rocks. The station T08A is located in the Alto Hospicio basin in the coastal cordillera at approximately $500 \mathrm{~m}$ a.s.1. On the other hand, the stations T07A and $\mathrm{T} 10 \mathrm{~A}$ are located in the eastern part of the coastal cordillera, at the limit with the central depression, on alluvial sediments of the Pampa del Tamarugal basin. Finally, the station PB11 is located in the northern part of the Pampa del Tamarugal basin (Pinto Morales et al. 2016).

\section{SEISMIC DATA: EVIDENCE FOR SITE EFFECTS}

As explained previously, in recent decades, a large number of seismic stations have been deployed in Northern Chile. The IPOC seismic network (see some examples of seismic stations in Fig. 2) is part of the Integrated Plate Boundary Observatory of Chile, a EuropeanChilean seismic network dedicated to the study of earthquakes and deformation in the continental margin. It is operated by the GFZ German Research Centre for Geosciences, the Institut de Physique du Globe de Paris (IPGP), the Chilean Seismological Center (CSN), the Universidad de Chile (UdC) and the Universidad Católica del Norte (UCNA; Geosciences \& CNRS-INSU 2006). The National Seismological Network (RSN in Spanish) comprises a set of over 95 multiparameter stations located in the Chilean territory, which includes broad-band seismometers, accelerometers and GPS sensors. Table 1 shows the details of the seismic stations in the study area used in this study and Fig. 2 shows their locations, including stations from both the IPOC and RSN networks.

In order to examine the signature of site effects in the seismic data, in this section we analyse three-component waveforms generated by the 2014 Iquique earthquake recorded by the RSN seismic network. We deconvolve the instrument's response from the waveforms and remove the mean and trend. The horizontal-component waveforms are rotated into radial $(\mathrm{R})$ and transverse $(\mathrm{T})$ directions. The data are filtered using a Butterworth bandpass filter of order 2 with four poles in various frequency bands from 0.01 to $20 \mathrm{~Hz}$.
Fig. 3 shows the processed waveforms for stations T05A, T06A, T03A, T08A and T07A. Stations T03A, T05A and T06 are located in Iquique in the coastal plain, station T08A is located in Alto Hospicio, which is located within the coastal cordillera approximately $500 \mathrm{~m}$ from the coastal cliff, and station T07A is located in the Pampa del Tamarugal Basin at the boundary zone between the coastal Cordillera and the central depression (Fig. 2, Table 1). In the waveforms, clear amplification is visible for stations T03A, T08A and T07A, most notably on the horizontal components, since they show larger amplitudes than stations at shorter epicentral distances. We note that the stations used in Fig. 3 all have about the same source-receiver azimuth, thus, source effects should be about the same for all stations. Given that these three stations are located either in the vicinity of the coastal cliff or in a sedimentary unit; it indicates that the ground motion amplification observed during the Iquique earthquake may be related to soil type or to the coastal cliff.

\section{SEISMIC WAVEFORM MODELLING}

To understand the effects of the topography and sedimentary intramountainous basins on the amplification of the seismic waves, we perform simulations of seismic wave propagation in the study region using the Cartesian version of SPECFEM3D, a software package that uses the spectral element method (SEM) to solve the 3-D wave equation at local or regional scales (Komatitsch \& Vilotte 1998; Komatitsch \& Tromp 1999; Komatitsch et al. 2010). The SEM is a highly accurate numerical method that uses a mesh of hexahedral finite elements on which the wavefield is represented in terms of high-degree Lagrange polynomials on Gauss-Lobatto-Legendre interpolation points. This method and the SPECFEM3D software have been widely employed to model seismic wave propagation using local, regional and global velocity models (e.g. Magnoni et al. 2014; Molinari et al. 2015; Parisi et al. 2018); as they combine the flexibility of the finite-element method with the accuracy of pseudospectral techniques. The flexibility of the mesh allows the implementation of complex geometries, topography, bathymetry and basement surfaces with minimal numerical dispersion, and with the advantage of traction-free boundary conditions (Faccioli 1991; Komatitsch \& Vilotte 1998; Komatitsch \& Tromp 1999; Komatitsch et al. 2004, 2010; Lee et al. 2009).

\subsection{Model implementation}

In this study, we use a mesh with a width of $145 \mathrm{~km}$, a length of $200 \mathrm{~km}$ and a depth of $60 \mathrm{~km}$, ranging from $19.25^{\circ} \mathrm{S}$ to $21.05^{\circ} \mathrm{S}$ and from $69.45^{\circ} \mathrm{W}$ to $70.85^{\circ} \mathrm{W}$. The number of elements on each side of the mesh is 320 in the east direction, 320 in the north direction and 120 in the depth direction, obtaining elements with lengths between 453 and $679 \mathrm{~m}$, making a total of 12288000 elements. This mesh configuration is chosen so that the source-receiver region considered is well covered enabling the accurate calculation of synthetic waveforms with frequencies up to $3.5 \mathrm{~Hz}$, while keeping a reasonable computational cost of the simulations. In order to validate the accuracy of our simulations, we have performed simulations with a finer mesh with 640 elements in the east direction, 640 elements in the north direction and 120 elements in the depth direction, with element lengths between 226 and 522 m, making a total of 49152000 elements. Supporting Information Fig. S1 compares waveforms obtained with these two different meshes filtered in frequency ranges between 0.1 and $2.0 \mathrm{~Hz}$. These graphs show good agreement between the two sets of synthetics for some representative stations. 


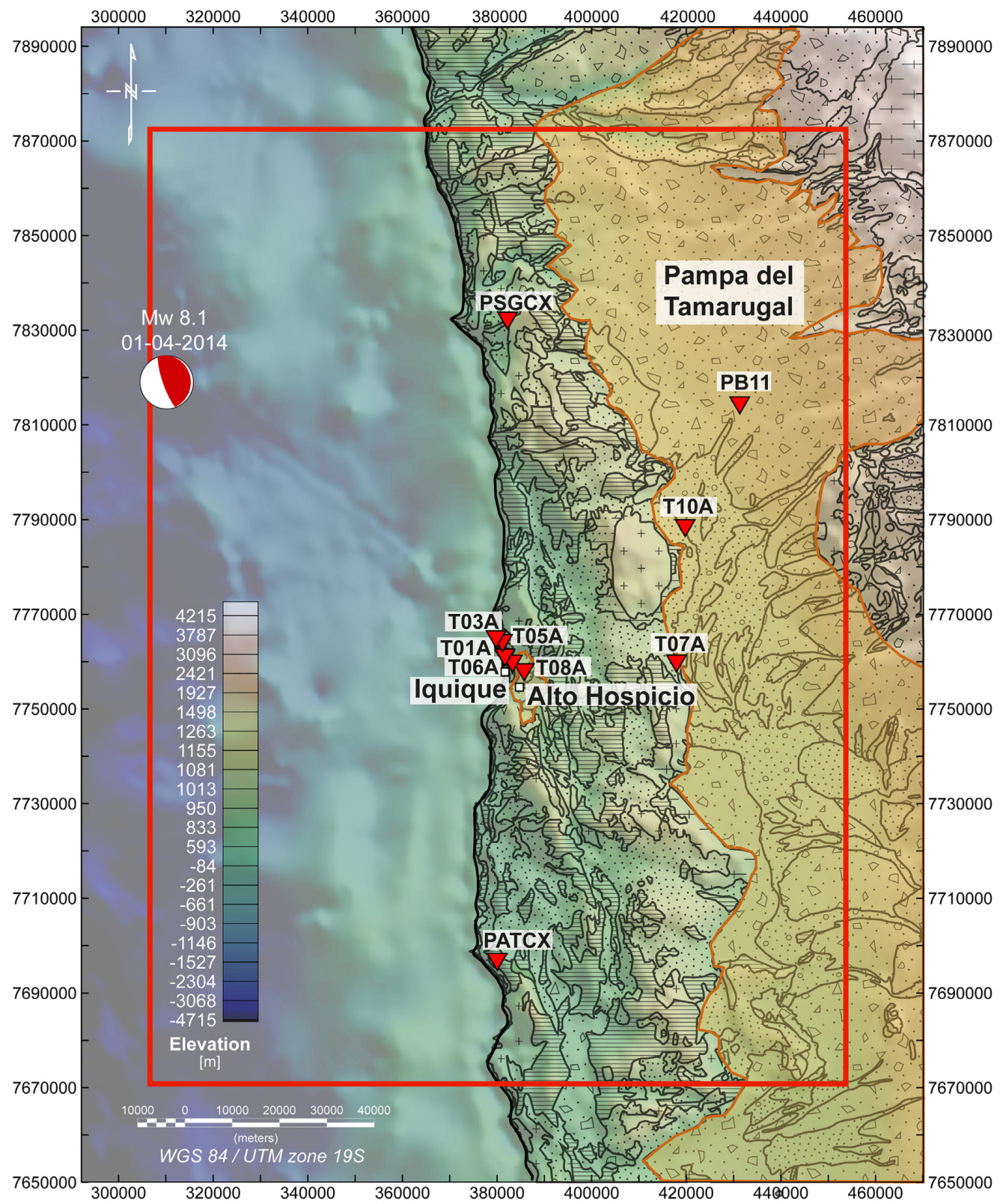

\section{Legend}

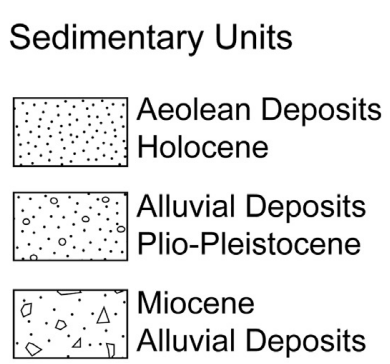

\section{Rock Units}
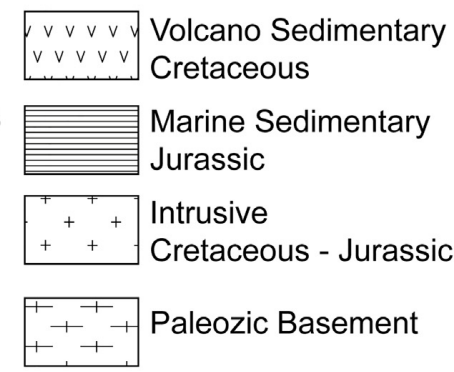

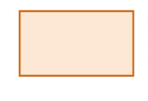

Alto Hospicio and Pampa del Tamarugal Intra-mountainous Basins

\section{Study Area}

Seismic Station

Focal Mechanism Iquique Earthquake

Figure 2. Geological map of the study area (red rectangle) above the SRTM topographic map in WGS84 datum 19S (Becker et al. 2009). The inverted red triangles show the locations of seismic broad-band stations from the IPOC and RSN seismic networks used in this study (see the main text for further details). The red beach ball represents the focal mechanism of the 2014 April 1 Iquique earthquake. The annotations 'Pampa del Tamarugal' and 'Alto Hospicio' highlight the locations of these sedimentary basins. 


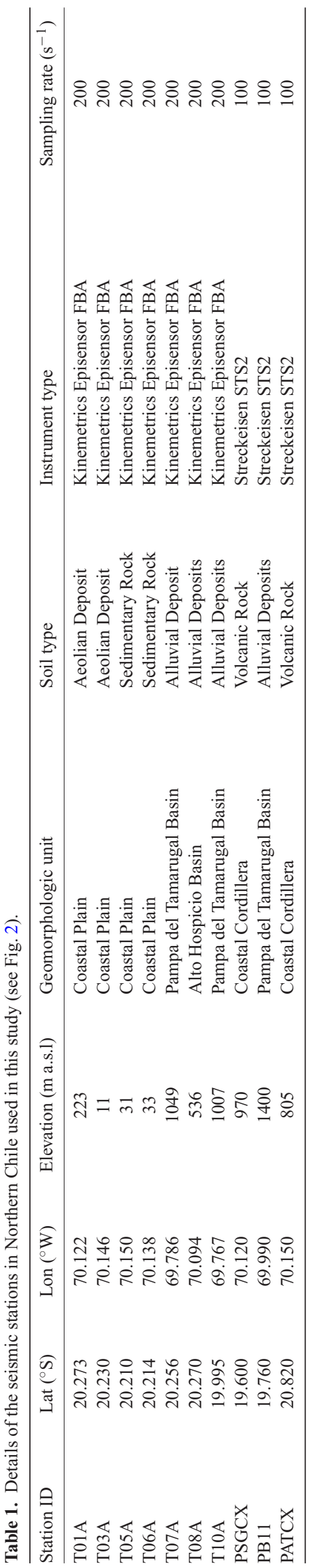

These results validate the accuracy of the meshes and justifying the use of the coarser mesh, which leads to computationally cheaper simulations by about a factor of six.

We use a 1-D earth model of $P$ - and $S$-wave speed that was used by León-Ríos et al. (2016) to determine the hypocentral locations of the Iquique earthquake sequence. It is a modification of a model built by Husen et al. (1999) for the Antofagasta region $(300 \mathrm{~km}$ south of Iquique), as presented in Fig. 4. We set the shear attenuation coefficient to 600 for all depths and use Stacey absorbing conditions for the four vertical faces and for the bottom face of the grid in order to simulate a semi-infinite regional medium of elastic elements and a free-surface condition at the top. The sampling interval is set at $0.005 \mathrm{~s}$ and the maximum resolvable frequency is $3.5 \mathrm{~Hz}$, as roughly 5 points per wavelength are needed to sample the wave field. The computations were performed on the UK's national supercomputing facility ARCHER using parallel programming that distributes the 320 mesh slices over 20 processors for each coordinate axis, using a total of 400 processors for a total of 12288000 elements. Each simulation had a duration of approximately $5 \mathrm{hr}$ on ARCHER.

To investigate the separate effects of topography and basins on seismic wave amplification we performed seismic wave propagation simulations using three different earth models:

(i) A flat model (i.e. with neither topography nor basins) using the $1-\mathrm{D}$ velocity model described above;

(ii) A model with topography and the 1-D velocity structure. We implemented the Shuttle Radar Topography Mission (SRTM) Digital Elevation Model (Becker et al. 2009) for our study region with a $90 \mathrm{~m}$ resolution in the surface of the grid. However, since the spacing of the mesh (which has element lengths between 453 and $679 \mathrm{~m}$ ) is coarser than the resolution of the DEM, the topography was smoothed when building the mesh, yet preserving the important features, such as the coastal cliff, as shown in Fig. 5(a). Moreover, Supporting Information Fig. S2 shows some illustrative examples of EW profiles, shown in Fig. 6, of the implemented topography compared with that in the DEM;

(iii) A basin model whereby two cuboids with different sizes and elastic properties are added to the topographic model. These two cuboids represent the Alto Hospicio and the northern part of the Pampa del Tamarugal basins, with density, $V_{\mathrm{p}}$ and $V_{\mathrm{s}}$ values related to sedimentary geological units (Teldford et al. 1990; Dentith \& Mudge 2014). The geometry of the basins was obtained from the previous studies of García-Pérez et al. (2018) and Viguier et al. (2018), both of which constrained the extension and depth of the sedimentary deposits filling the basins using geophysical data. Table 2 shows the geometric parameters that were used to simulate the basins in the mesh, in which the Alto Hospicio (AH) basin is smaller ( $8 \mathrm{~km}$ in length, $2 \mathrm{~km}$ in width and $500 \mathrm{~m}$ in depth), being located in the middle of the mesh next to the coastal cliff, while the northern part of the Pampa del Tamarugal (PT) basin is larger, being located in the upper right part of the mesh. As explained previously, in this study we focus on the northern part of the Pampa del Tamarugal basin, as it is the deepest and better constrained part of the basin. Fig. 5(b) shows the tridimensional basin model.

\subsection{Earthquakes studied}

For each model used, we consider two small-to-moderate magnitude earthquakes using the source parameters and hypocentral locations obtained from the analysis of León-Ríos et al. (2016; Table 3). These earthquakes occurred as part of the aftershock sequence of the Iquique earthquake and their hypocentres were located at 34 and 


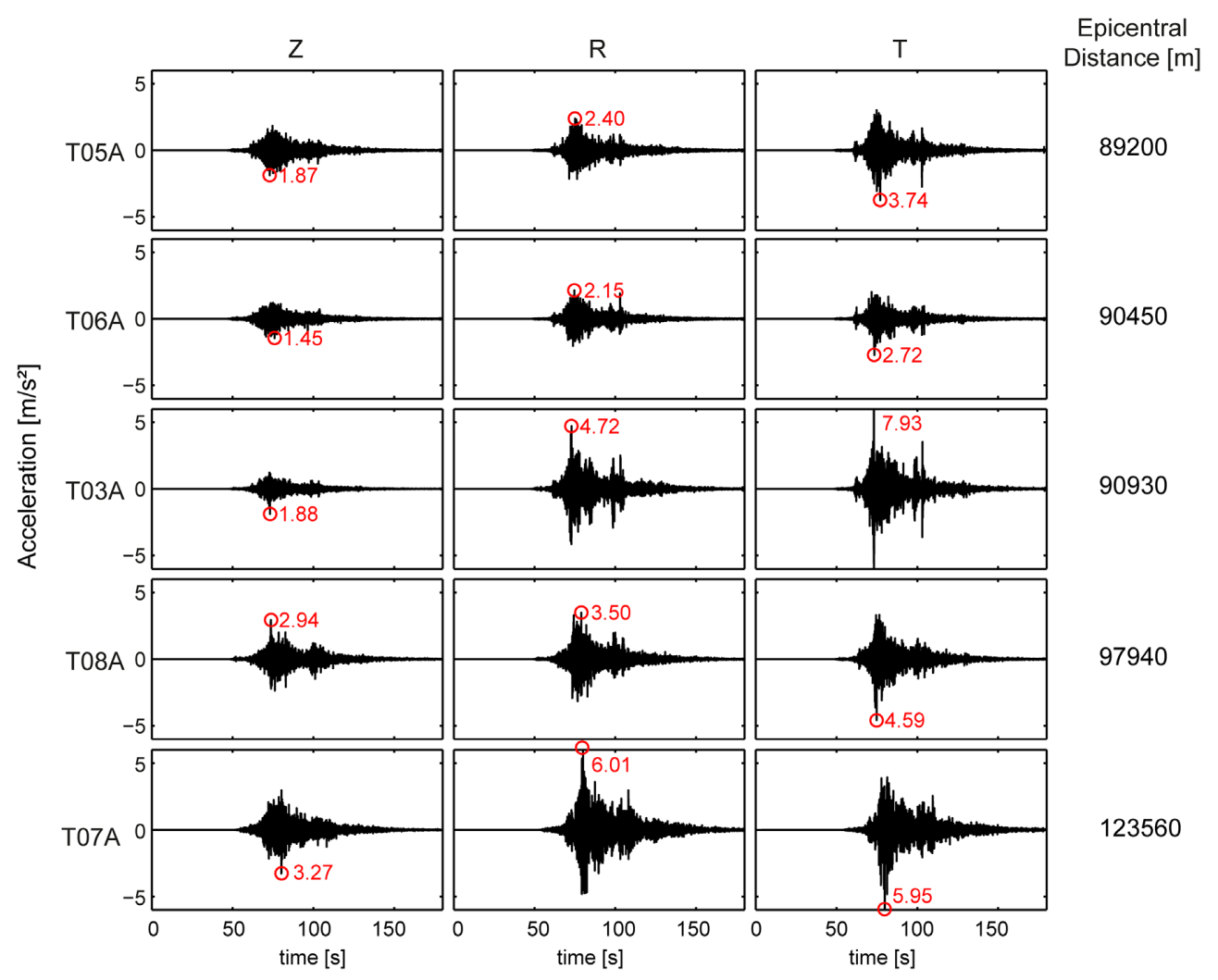

Figure 3. Examples of local acceleration waveforms for the 2014 April $1 M_{\mathrm{W}} 8.1$ Iquique earthquake measured by five three-component seismic stations located at various epicentral distances, showing evidence for site effects (see Fig. 2 for the location of the stations). The waveforms were filtered using a Butterworth bandpass filter of order 2 with four poles in various frequency bands from 0.1 to $20 \mathrm{~Hz}$. The vertical (Z, left), radial (R, middle) and transverse (T, right) components for the five stations are shown using the same horizontal and vertical scales. The red circles represent the maximum peak value for each trace, with the value also annotated in red.

$49 \mathrm{~km}$ depth, close to the emerged continental forearc, as shown in Fig. 6. The events were earthquakes with focal mechanisms very similar to that of the main shock but with smaller magnitudes of $M_{\mathrm{w}} 5.4$ and 4.5 , respectively. We choose this magnitude range to avoid the extended source complexity effects which are associated with larger earthquakes while ensuring a good signal-to-noise ratio of the observed waveforms.

As the number of stations used in the SEM simulations does not increase their computational cost, we compute synthetic seismograms both for the locations of real stations in the region (red triangles in Fig. 6) and for a number of hypothetical stations (blue and yellow triangles in Fig. 6). The synthetic stations in blue represent stations which are situated at the same latitude as a real station and are positioned at various longitudes to allow a west-east profile to be constructed, whereas the synthetic stations in yellow are used to construct completely synthetic profiles in order to increase the spatial coverage across the mesh.

\section{MODELLING RESULTS}

\subsection{Topographic model simulation}

To investigate the effects of topography on seismic wave propagation in the study region, we show the simulations performed for the 2014 July $13 M_{\mathrm{w}} 5.4$ earthquake (depth $\sim 34 \mathrm{~km}$; Table 3) using the flat model and the topographic model combined with the 1-D earth structure described in Section 4.1. Fig. 7 and Supporting Information Figs S3-S6 compare the synthetic waveforms obtained for both models filtered in four different frequency ranges between 0.1 and $2.0 \mathrm{~Hz}(0.1-0.2 \mathrm{~Hz}, 0.2-0.5 \mathrm{~Hz}, 0.5-1.0 \mathrm{~Hz}$ and $1.0-2.0 \mathrm{~Hz})$. Fig. 7 shows the waveforms filtered between 0.5 and $1.0 \mathrm{~Hz}$ for some stations along the profile PSGCX (see location in Fig. 6), in which three main effects related to topography can be seen. First, as expected, there is a small time-shift between the two sets of waveforms due to the difference in altitude between the flat and the topographic model. Second, differences in amplitude can be observed between the three-component waveforms at some stations (e.g. PSGX6 and PSGCX7) close to important topographic features such as the coastal cliff. Finally, the simulations that include topography show reflected waves produced in the coastal cliff, which appear as a secondary arrival in the vertical and radial components for some stations (see stations PSGCX8, PSGCX9, PSGCX10 marked with red arrow in Fig. 7) and have the same or slightly larger amplitudes than the main waveforms (see stations PSGCX12, PSGCX14, PSGCX16 and PSGCX18 marked with red arrow in Fig. 7).

To estimate the ground motion amplification generated by the topography, we calculate the ratio between the total energy obtained from the velocity seismograms, filtered between 0.1 and $3.5 \mathrm{~Hz}$, for the topographic and flat models and for each station. The total energy is the integral of the square of the ground velocity of the three components for each type of seismogram. Then we compute the ratio of the total energies for the topographic and flat models. The energy amplification-ratio between the topographic model and the flat model in every simulated station is shown as coloured circles from light-blue to pink, as shown in Fig. 8. We note that the approach that we use to estimate amplification is different than others in the 


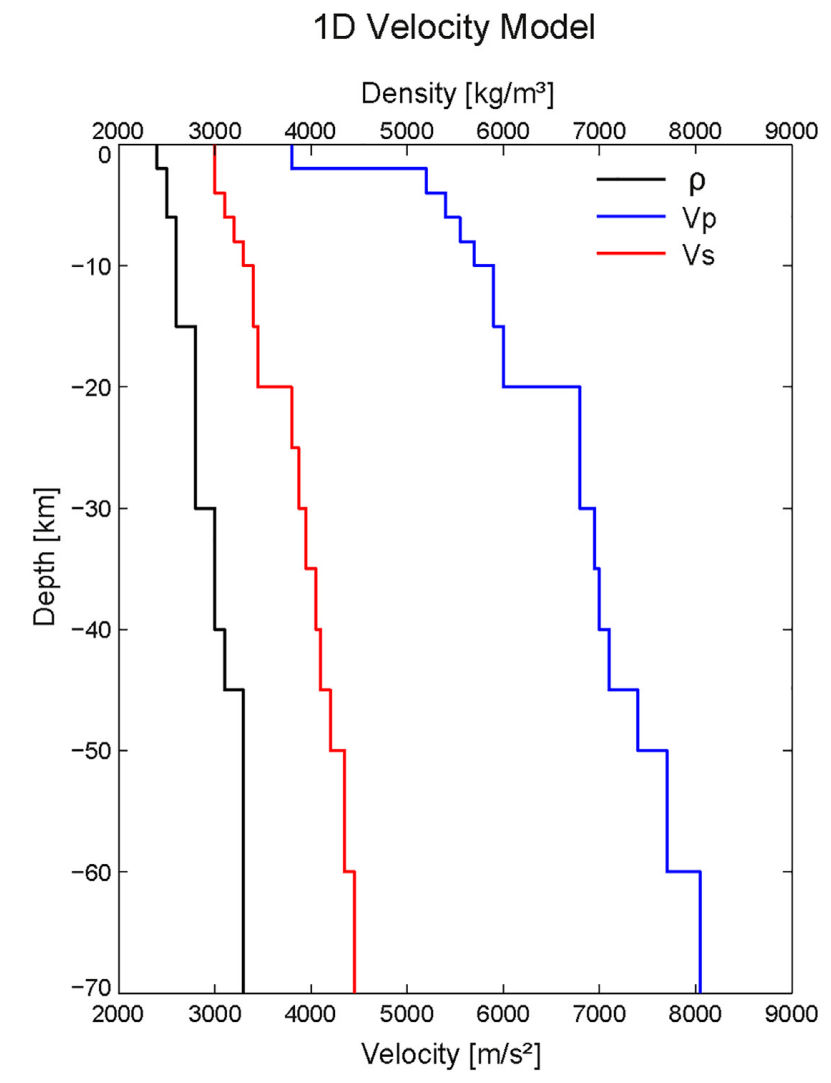

Figure 4. The 1-D model of $V_{\mathrm{p}}, V_{\mathrm{s}}$ and density (Husen et al. 1999; LeónRíos et al. 2016) used in this study.

literature (e.g. Boore 1972; Olsen 2000; Poursartip et al. 2017), which are often based on ratios of peak ground velocity. In this study occasionally the peak velocity of the secondary waves is larger than that of the main waveform (e.g. Fig. 7), which is problematic. Hence, we prefer to estimate amplification based on energy ratios obtained from three-component seismograms.

In Fig. 8, a clear spatial relationship can be observed for amplification-ratio $>1$ (circles coloured in yellow, orange, red and pink in Fig. 8) which includes the coastal cordillera, which is limited to the west by the coastal cliff and the coastline (black line). On the other hand, we observe that topographic deamplification ratio $<1$ (light-blue and green coloured circles in Fig. 8) is mainly spatially related to the offshore area and valleys located within the coastal cordillera (green regions in Fig. 6). For simplicity, in the remainder of this paper we shall refer to amplification-ratio $>1$ as amplification and to deamplification ratio $<1$ as deamplification. The amplification reach values of up to 2.16 (i.e. amplification of 116 per cent) and deamplification as low as 0.55 (i.e. de-amplification of 45 per cent).

In Fig. 9, amplification-ratio maps for frequencies ranges between $0.1-0.2 \mathrm{~Hz}, 0.2-0.5 \mathrm{~Hz}, 0.5-1.0 \mathrm{~Hz}$ and $1.0-2.0 \mathrm{~Hz}$ are shown. In these maps, maximum amplification-ratios of 1.35 , $1.53,3.38$ and 3.6 are observed for the frequency ranges of $0.1-$ $0.2 \mathrm{~Hz}, 0.2-0.5 \mathrm{~Hz}, 0.5-1.0 \mathrm{~Hz}$ and $1.0-2.0 \mathrm{~Hz}$ respectively. The results show amplifications produced in the surrounding area of the coastal cliff increase with the frequency, with the lowest values being observed in the lowest frequency range, that is, $0.1-$ $0.2 \mathrm{~Hz}$, and the largest values of 3.6 being observed in the frequency ranges of 1.0-2.0 Hz. In the same way, deamplification is observed in stations near the coastal line and in the coastal cordillera, which is spatially related to the coastal plains and valleys into the coastal cordillera. For low frequency ranges, $0.1-0.2 \mathrm{~Hz}$ and $0.2-$ $0.5 \mathrm{~Hz}$, an area of deamplification is observed near the coastal cliff. However, this deamplification disappears at higher frequencies, for which a large area of deamplification develops inland near valleys.

\subsection{Basin model simulation}

In order to investigate the effect of the region's basins on the waveforms, in this section we show the results of the simulations performed for the 2014 July $13 M_{\mathrm{w}} 5.4$ earthquake using the 1-D velocity model with topography and the $1-\mathrm{D}$ velocity model with topography and basins, in which sedimentary basins in the region are simulated as described in Section 4.1 and represented in Fig. 6 (blue rectangles). Fig. 10 compares synthetic waveforms for some stations, filtered between 0.5 and $1.0 \mathrm{~Hz}$, obtained from both models for the stations along the T08A profile, which crosses the Alto Hospicio basin from west to east. Supporting Information Figs S7S10 present the synthetic waveforms for all the stations along the T08A profile filtered between $0.1-0.2 \mathrm{~Hz}, 0.2-0.5 \mathrm{~Hz}, 0.5-1.0 \mathrm{~Hz}$ and $1.0-2.0 \mathrm{~Hz}$. From a comparison of the two types of synthetic waveforms in Fig. 10 it can be seen that the differences between them are not significant until the seismic wavefield reaches the stations T08A7 and T08A8, which are located in the area surrounding the Alto Hospicio basin. These two stations show amplification of the seismic wavefield in the vertical and transverse components. However, the amplitude of the radial component is smaller for the model with topography and basins (blue trace in Fig. 10) than for the topography-only model (red trace in Fig. 10). On the other hand, the seismic stations further to the east (from T08A9 to T08A19) show slight differences in amplitude between the transverse component waveforms obtained for the two models, which is probably due to the reflection of waves in the Alto Hospicio basin (see from $\sim 19 \mathrm{~s}$ onward in movie basin en the supplementary material). Supporting Information Figs S11-S14 present synthetic waveforms filtered between $0.1-0.2 \mathrm{~Hz}, 0.2-0.5 \mathrm{~Hz}, 0.5-1.0 \mathrm{~Hz}$ and $1.0-2.0 \mathrm{~Hz}$ for the PB11 profile, where the amplification effects of the Pampa del Tamarugal basin are clearly shown, where it is possible to observe amplification of the waves and that total duration of the waveforms qualitatively increases.

As in the previous section, Fig. 11 shows a map with the total energy ratio between the model with topography and basins and the topography-only model represented in coloured circles. This ratio was computed in the same way as in Section 5.1. Fig. 11 shows that there is clear amplification in the stations located within basins (blue rectangles), with the amplification ratio reaching up to 2.9 (representing a 190 per cent increase in amplitude), as well as amplification ratios of up to 1.25 ( 25 per cent increase in amplitude) in stations in the far southeast region of the study area. Additionally, Fig. 11 also shows that there is clear deamplification up to 0.75 (25 per cent decrease in amplitude) in areas surrounding the basins. The energy ratio maps for frequency ranges of $0.1-0.2 \mathrm{~Hz}, 0.2-$ $0.5 \mathrm{~Hz}, 0.5-1.0 \mathrm{~Hz}$ and $1.0-2.0 \mathrm{~Hz}$ are presented in Fig. 12 showing that the amplification generally increases with frequency, reaching a maximum value of 3.9 for stations located in the Pampa del Tamarugal basin and a maximum value of 1.8 for the station located in the Alto Hospicio basin for the frequency range 1.0-2.0 Hz. 


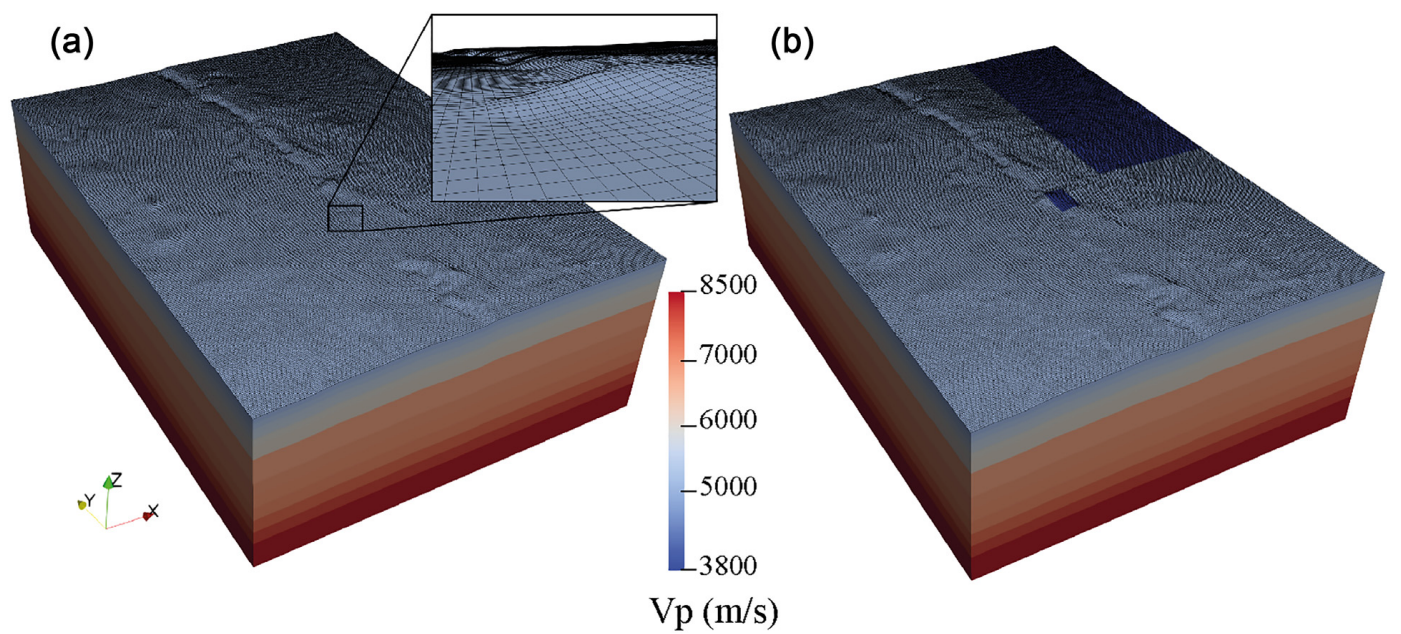

Figure 5. 3-D view of the mesh used in this study, which is $200 \mathrm{~km}$ long, $145 \mathrm{~km}$ wide and $60 \mathrm{~km}$ deep. The 1-D $V_{\mathrm{p}}$ values which were implemented are also shown. (a) 1-D velocity model for $V_{\mathrm{p}}$ ranging from 3800 to $8050 \mathrm{~m} \mathrm{~s}^{-1}$ with topography. (b) 1-D velocity model with topography and basins, with $V_{\mathrm{p}}$ ranging from 3800 to $8050 \mathrm{~m} \mathrm{~s}^{-1}$. Both basins considered are shown in dark blue: the smaller Alto Hospicio basin $(8 \mathrm{~km} \mathrm{long,} 2 \mathrm{~km}$ wide and $500 \mathrm{~m}$ deep) and the larger Pampa del Tamarugal basin (105 km long, $50 \mathrm{~km}$ wide and $1000 \mathrm{~m}$ deep).

\section{COMPARISON WITH REAL DATA}

In this section, we compare the different synthetic waveforms obtained in this study with real data for the 2014 April $2 M_{\mathrm{w}} 4.5$ and the 2014 July $13 M_{\mathrm{w}} 5.4$ earthquakes. As explained previously, these earthquakes were chosen due to the similarity of their focal mechanisms with the main 2014 April $1 M_{\mathrm{w}} 8.1$ Iquique earthquake, but their smaller magnitudes allow us to avoid the extended source complexity effects in the real data and visualize more precisely site effects. As the RSN network provides acceleration data, we doubledifferentiate the IPOC data and all the synthetic seismograms to obtain acceleration values for all the stations considered. The real data and the synthetic seismograms are processed in the same way by removing the trend and the mean and by rotating the horizontal components into radial and transverse components. Finally, all the waveforms are band pass filtered with a four-pole two-pass Butterworth filter for different frequency ranges between 0.1 and $2.0 \mathrm{~Hz}$. We compare the synthetic and real waveforms by computing the cross-correlation between the waveforms to obtain the phase misfits and for the amplitude misfits we calculated the square root of the ratio between the sum of the square of the amplitudes in the synthetics and the real data. In this way, for the phase misfit values close to 0 and for the amplitude misfit values close to 1 are considered good fits.

\subsection{Simulation of the 2014 April $2 M_{\mathrm{w}} 4.5$ Earthquake}

The $M_{\mathrm{w}} 4.5$ earthquake of 2014 April 2 was located at a depth of $49 \mathrm{~km}$, with the hypocentre located close to the coastline. To compare the real data and the computed waveforms, we simulate this earthquake using the different models as explained in Section 4.1. In this section we show the simulations using the 1-D velocity model with topography and the 1-D velocity model with both topography and basins.

The comparison of the synthetic waveforms obtained from these simulations with the corresponding real data is shown in Fig. 13 for the frequency range between $0.2-0.5 \mathrm{~Hz}$ (Supporting Information Figs S15-S18 show the comparison for the frequency ranges $0.1-0.2 \mathrm{~Hz}, 0.2-0.5 \mathrm{~Hz}, 0.5-1.0 \mathrm{~Hz}$ and $1.0-2.0 \mathrm{~Hz}$ ). The results for the different models show that there are only slight differences between the waveforms obtained for the topography and the topography and basins models for the stations T03A, T07A, PSGX and PATCX, while more significant differences are observed for those stations located within or around the modelled basins (T08A, T10A and PB11). Overall, good fits (time phase misfit values close to $0 \mathrm{~s}$ and amplitude misfit values close to 1) are obtained between the real and the synthetic waveforms for stations T07A and PSGCX, with some time-shifts and differences in amplitude, mostly in the radial and transverse components. Station T10A also shows good fit for the 1-D topography model, while the fit gets worse for the 1-D topography and basins model. For stations T03A, T08A, PB11 and PATCX, larger differences are observed between the real data and the synthetic seismograms (phase misfits values above $0.5 \mathrm{~s}$ and amplitude misfit values less than 0.5 , meaning that the amplitude of the synthetics are less than half the amplitude of the real data). Stations PB11 and T08A are located in the Pampa del Tamarugal and Alto Hospicio basins, respectively (Fig. 2) and, despite the fact that the wave amplitudes obtained using the model with topography and basins show differences to those obtained using the topographic model, the real data is much more complex with larger amplitudes than the synthetic waveforms for the basin model. The disagreement between the real data and the synthetic waveforms obtained using the basin model is probably due to the simplified geometry and elastic properties of the basin used in our simulations. On the other hand, stations T03A and PATCX show larger differences in phase and amplitude between the real data and the synthetics, probably related to the proximity of these stations with the coastal cliff. When considering different frequency ranges (see Supporting Information Figs S15-S18), the differences between the real and synthetic waveforms increases as frequency increases, with notable good agreements for the frequency range between $0.1-0.2 \mathrm{~Hz}$, but as frequency increases the observations are more complex and often having larger amplitudes than the synthetics (see Supporting Information Fig. S23, showing large amplitude misfits for frequency ranges between 0.5 and $2 \mathrm{~Hz}$ ). Hence, the amplification in real data is larger than in the synthetics for the higher frequencies, which is likely due to $3-\mathrm{D}$ small-scale heterogeneity that is not yet constrained and not accounted for in the modelling. 


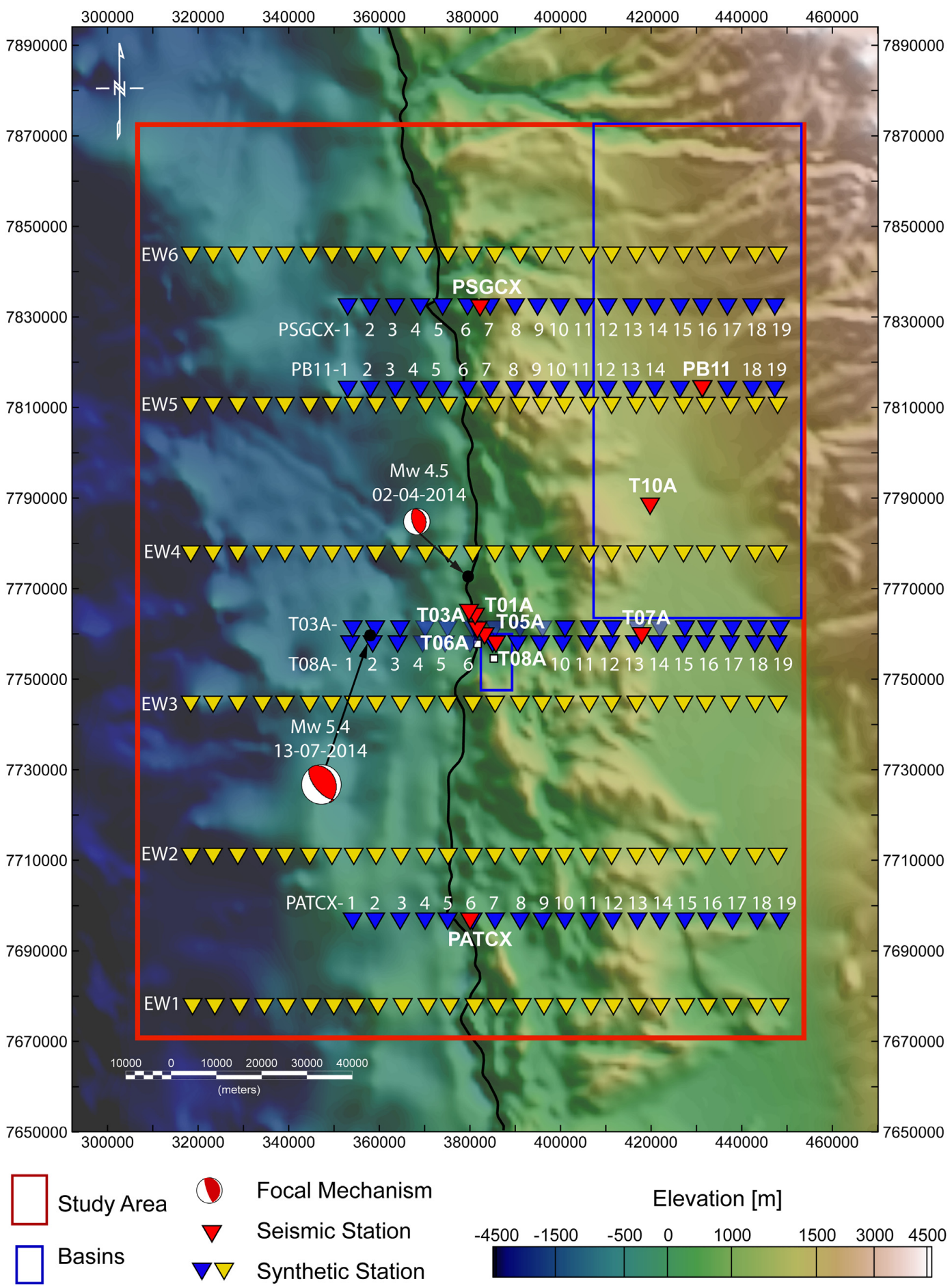

Figure 6. SRTM topographic map (Becker et al., 2009) of the study area in WGS84 datum 19S including the focal mechanisms (León-Rios et al. 2016) of the two aftershock earthquakes considered in this study (red beach balls) and the locations of real seismic stations in the region (red inverted triangles) as well as hypothetical stations (blue and yellow inverted triangles) aligned along lines of constant latitude. Valleys correspond to green colours while brown colours correspond to peaks in the Coastal Cordillera.

Table 2. Basin model parameters. AH denotes the Alto Hospicio basin and PT denotes the Northern part of the Pampa del Tamarugal basin (see Fig. 5b).

\begin{tabular}{lcccccc}
\hline Basin & $\begin{array}{c}\text { Density }(\mathrm{kg} \\
\left.\mathrm{m}^{-3}\right)\end{array}$ & $V_{\mathrm{p}}\left(\mathrm{m} \mathrm{s}^{-1}\right)$ & $\begin{array}{c}V_{\mathrm{s}}(\mathrm{m} \\
\left.\mathrm{s}^{-1}\right)\end{array}$ & Length $(\mathrm{km})$ & Width $(\mathrm{km})$ & Depth $(\mathrm{km})$ \\
\hline AH & 2400 & 3800 & 2500 & 8 & 2 & 0.5 \\
PT & 2400 & 3800 & 2500 & 105 & 50 & 1 \\
\hline
\end{tabular}


Table 3. Source parameters of the earthquakes used in this study.

\begin{tabular}{|c|c|c|c|c|c|c|c|c|}
\hline \multirow[t]{2}{*}{ Date } & \multirow[t]{2}{*}{ Earthquake ID } & \multicolumn{3}{|c|}{ Location } & \multicolumn{4}{|c|}{ Focal mechanism } \\
\hline & & Lat $\left(^{\circ}\right)$ & Lon $\left(^{\circ}\right)$ & Depth $(\mathrm{km})$ & $M_{\mathrm{w}}$ & Strike $\left(^{\circ}\right)$ & $\operatorname{Dip}\left({ }^{\circ}\right)$ & Rake $\left(^{\circ}\right)$ \\
\hline 2014-04-02 & 20140402070345 & -20.14 & -70.15 & 49 & 4.5 & 350 & 30 & 95 \\
\hline 2014-07-13 & 20140713205414 & -20.25 & -70.36 & 34 & 5.4 & 140 & 55 & 80 \\
\hline
\end{tabular}

\subsection{Simulation of the 2014 July $13 M_{\mathrm{w}} 5.4$ earthquake}

For the 2014 July $13 M_{\mathrm{w}} 5.4$ earthquake, as in the previous section, we perform simulations using the models explained in Section 4.1. In this section we show the simulation using the 1-D velocity model with topography and the 1-D velocity model with both topography and basins.

Fig. 14 shows the comparison of the synthetic waveforms obtained from these simulations with the corresponding real data for the frequency range between $0.2-0.5 \mathrm{~Hz}$ and overall there is a good fit between the simulated and real data for stations T01A, T08A and T07A (phase misfit values close to 0 seconds and amplitude ratio misfit values close to 1 for almost all components), whereas stations PATCX, PSGCX and PB11 present poorer fits, with phase misfit values above 1 second in some components and amplitude misfits less than 0.5 or higher to 1.5 for some components. Time-shifts and some differences in amplitude are observed between the simulated waveforms using the topographic model and the basin model for stations T01A and T08A, which can be attributed to the simulated Alto Hospicio basin; and for station PB11, related to the simulated Pampa del Tamarugal basin. Similar to the $M_{\mathrm{w}} 4.5,2014$ April 2 event, the differences between the real and simulated waveforms increase with increasing frequency range (Supporting Information Figs S19-S22 and cross-correlation and amplitude ratio misfits in Supporting Information Fig. S23) showing that synthetic waveforms perform less well in reproducing the complexity of real data at frequencies above $0.5 \mathrm{~Hz}$.

Moreover, the fit between the real and simulated waveforms deteriorates with increasing epicentral distance (e.g. PSGCX and PB11; see Supporting Information Fig. S23 showing the waveform phase and amplitude misfits as a function of epicentral distances, where it is possible to see that the misfits deteriorate with epicentral distance and with increasing frequency). This shows that the 1-D velocity model used in this study is only appropriate for short epicentral distances. For larger distances, a more complex velocity model is needed, as the shallow depth of the hypocentre and the large distance from the coastal line of the 2014 July 13 earthquake leads to shallower source-receiver paths, which are strongly affected by small-scale crustal heterogeneity. Moreover, we also note that e.g. for station PSGCX, the ray paths for the 2014 July 13 earthquake are mostly oceanic while those for the 2014 April 2 event are mostly continental, which may also explain the differences in data fit for the two events.

\section{DISCUSSION}

\subsection{Topography effects}

Our study shows that topography modifies the seismic ground motion response in Northern Chile by changing the amplitude and duration of waveforms due to reflections generated by the topographic features (see time 12-15 s Supporting Information Movie $\mathrm{S} 1$ and Fig. 7, where some examples of reflections are highlighted by some arrows). These reflected waves increase the amplitude of the incident waves at the top of the topographic feature and propagate to the surrounding areas. As the distance between the topographic feature that produced the reflected wave and the observation point increases, the time separation between the incident and the reflected wave also increases, which in turn increases the duration of ground motion. Our results show that the amplitude of the reflected waves can be larger than the incident waves in some locations (see e.g. stations PSGCX-12, PSGCX-14, PSGCX-16 in Fig. 7 and Supporting Information Fig. S4), having important implications for seismic hazard in locations close to topographic features (Sánchez-Sesma \& Campillo 1993).

Previous studies, using displacement, acceleration and acceleration response spectra, reported topographic seismic amplification factors between 2 and 75 per cent, and found that amplification generally occurs at the slopes and at the top of topographic features whereas deamplification occurs at the bottom of slopes (e.g. Boore 1972; Bouchon et al. 1996; Paolucci 2002; Buech et al. 2010). In this study, we found that, for the frequency range $0.1-$ $3.5 \mathrm{~Hz}$, the energy amplification factor between the flat and topographic models reaches up to 2.2 (amplification of 120 per cent) and that areas of amplification (i.e. amplification factor $>1$ ) are strongly spatially related with the top of topographic features such as the coastal cordillera (Figs 7 and 8). On the other hand, areas of deamplification are observed in valleys formed between hills, where amplification factors can reach values of 0.6 (i.e. 40 per cent deamplification), which agrees with the aforementioned studies.

The analysis of different frequency ranges shows that, for stations located east of the coastline, the degree of amplification increases as the frequency increases, and the amplification is spatially related to the coastal cliff and the coastal cordillera. The results also suggest that areas of amplification and deamplification are related to the size of the topographic features, where large topography features such as the coastal cliff (500-1000 m high) or the coastal cordillera (50000 $\mathrm{m}$ width) produce major effects in the $0.1-0.5 \mathrm{~Hz}$ frequency range, while smaller features such as hills and valleys in the coastal cordillera (with $\sim 50-100 \mathrm{~m}$ heights and $\sim 1000-3500 \mathrm{~m}$ width), produce effects in the 1.0-2.0 Hz frequency range (see Fig. 9). The dependency between seismic amplification due to topography and frequency has been investigated in several studies. For example, in the Little Red Hill experimental study presented by Buech et al. (2010), their frequency-domain analysis shows a maximum amplification at about $5 \mathrm{~Hz}$, a frequency close to the first resonant harmonic frequency equal to the half-width or the height of the edifice. In the same way, the effects observed for a 3-D ellipsoid hill studied by a semi-analytical semi-numerical method show that amplification occurs at and near the top of the hill over a broad range of frequencies, and the maximum amplification value depends on the geometry of the features (Bouchon et al. 1996). In general, the frequency of maximum amplification corresponds to the wavelength comparable with the mountain width (Geli et al. 1988 and 

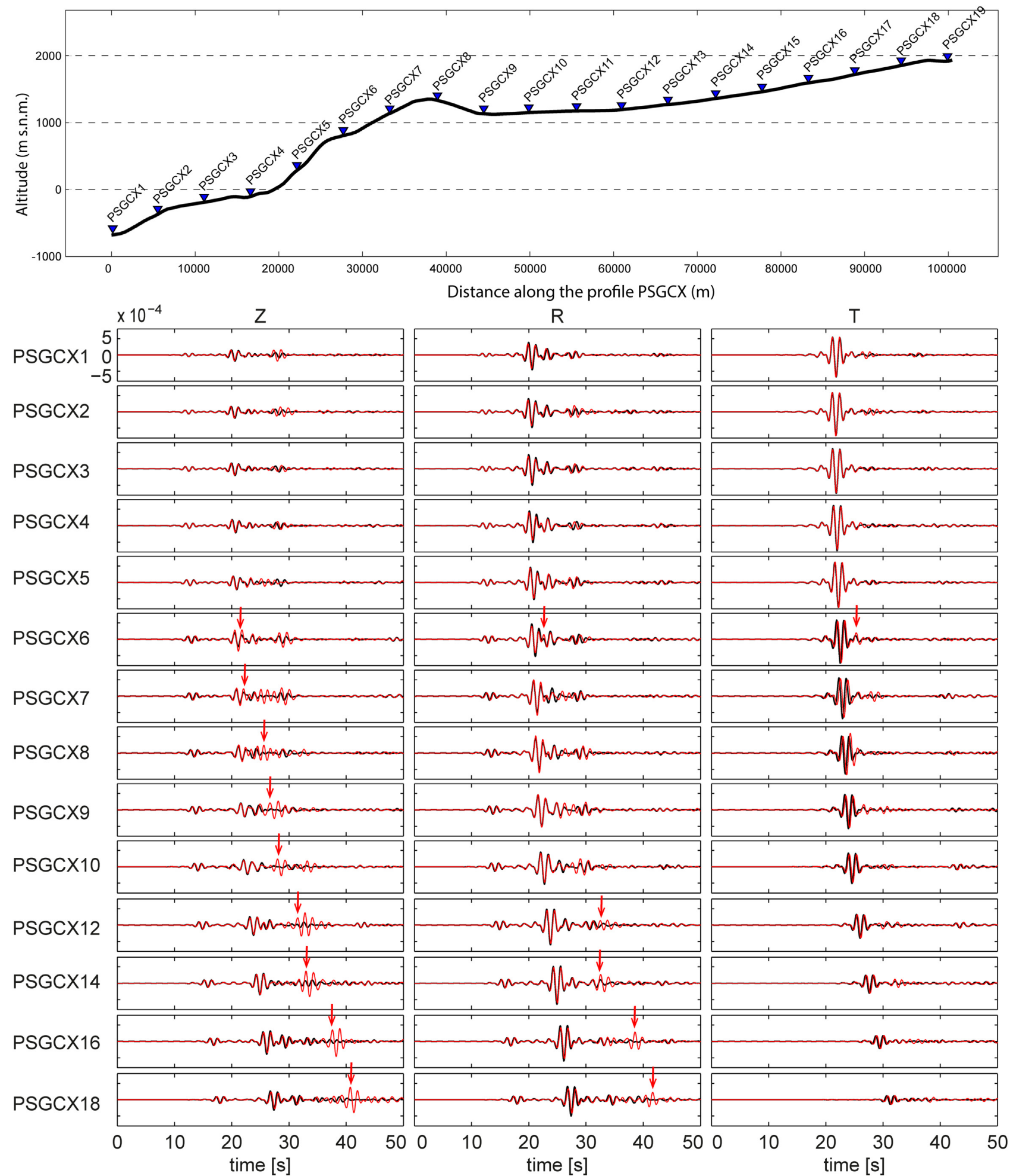

Figure 7. Top: Topography of the PSGCX profile (Fig. 6). Bottom: Comparison of synthetic seismograms computed using the 1-D flat model (black line) and the 1-D model with topography (red line) for the 2014 July 13 earthquake. The synthetic seismograms are all bandpass filtered between 0.5 and $1.0 \mathrm{~Hz}$. The processed waveforms for the vertical (left), radial (centre) and transverse (right) components are shown for 14 of the 19 stations along the PSGCX profile (Fig. 6). Red arrows indicate secondary waves produced by topography.

references therein), which is consistent with the results obtained in this study.

Our results also agree with the findings of Lee et al. (2009), who investigated seismic amplification due to topography using the SEM. They used a LiDAR digital terrain model (DTM) of the Yangminshan region in Taiwan to implement a high-quality topographic model using a $4 \times 4 \times 10 \mathrm{~km}^{3}$ mesh with resolution of $2 \mathrm{~m}$. They obtained PGA amplification of around 50 


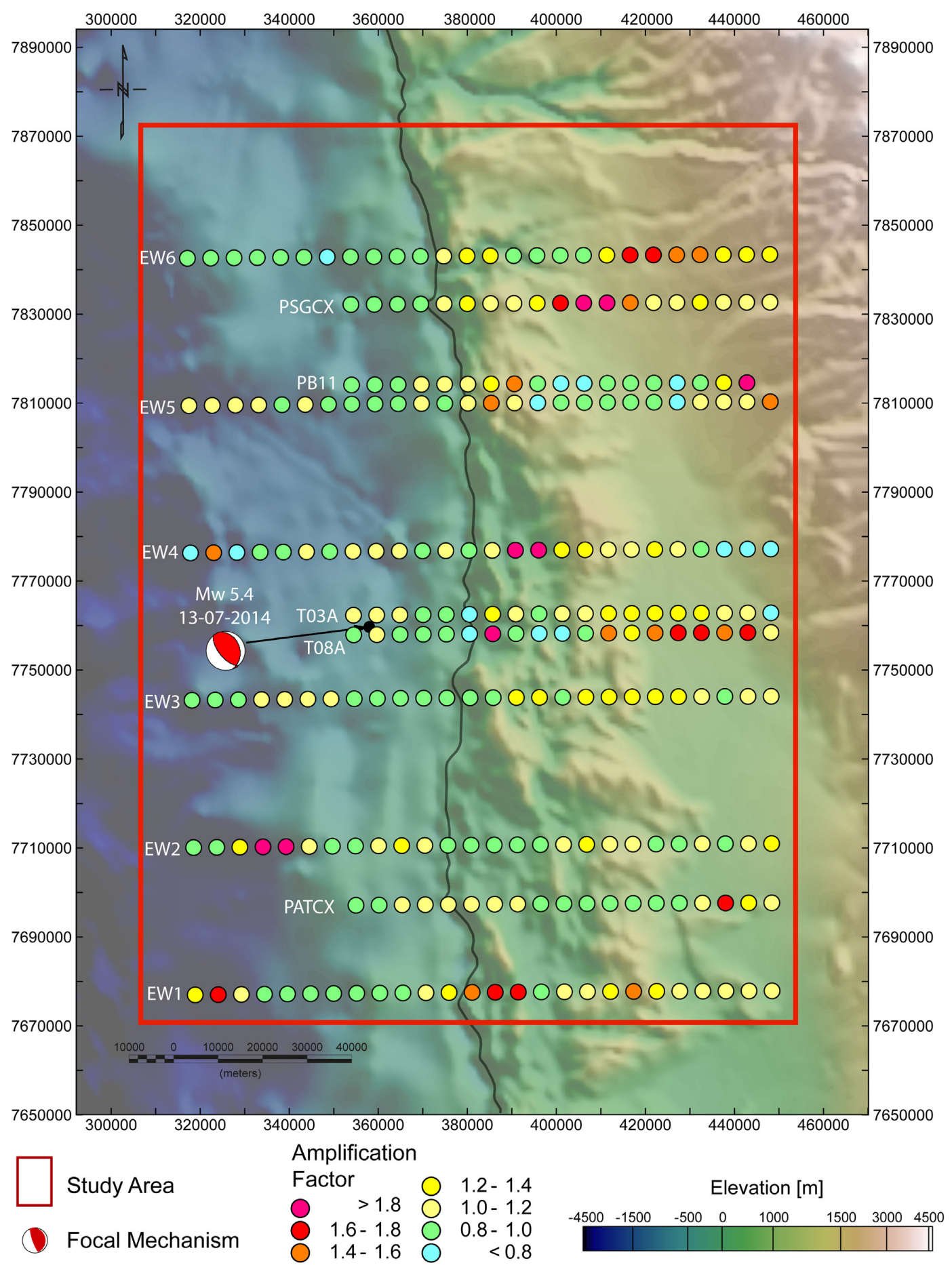

Figure 8. Map showing the energy amplification ratio for the frequency range between 0.1 and $3.5 \mathrm{~Hz}$ in the velocity waveforms between synthetic seismograms obtained using the flat model and the model with topography. The map shows coloured circles for each station location, in which the colours represent the calculated amplification factor with values between $<0.8$ and $>1.8$. Values above 1 represent relative amplification between the flat and topography models, while values below 1 represent relative deamplification. The beach ball represents the $M_{\mathrm{W}} 5.42014$ July 13 earthquake. The grey-shaded elevation map shows the geomorphological features related to the coastal cliff and the coastal cordillera to the east of the coastal line (black line).

per cent due to variations in topography in mountainous areas, which agrees with our results, despite the fact that we used a lower-resolution mesh $(\sim 450-680 \mathrm{~m})$ in a much larger domain $\left(145 \times 200 \times 60 \mathrm{~km}^{3}\right)$.

\subsection{Basin effects}

As expected, we found that basins have a significant impact on the ground motion response: they increase the amplitude and duration 

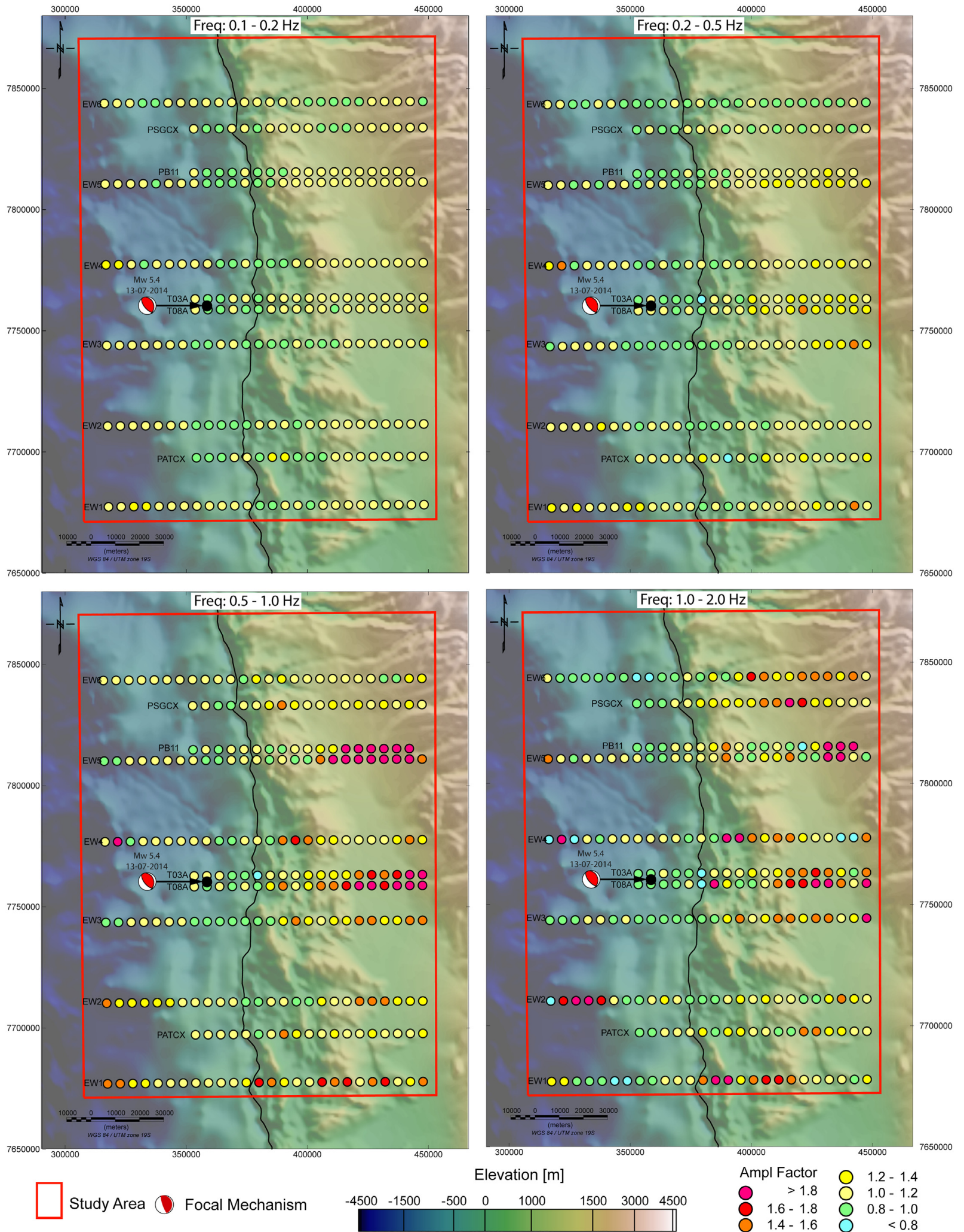

Figure 9. Amplification ratio maps between flat and topography models for frequency ranges between $0.1-0.2 \mathrm{~Hz}, 0.2-0.5 \mathrm{~Hz}, 0.5-1.0 \mathrm{~Hz}$ and $1.0-2.0 \mathrm{~Hz}$. The maps show coloured circles for each station location, in which the colours represent the calculated amplification factor. Values above 1 represent relative amplification between the flat and topography models, while values below 1 represent relative deamplification. The beach ball represents the $M_{\mathrm{W}} 5.42014$ July 13 earthquake. The grey-shaded elevation map shows the geomorphological features related to the coastal cliff and the coastal cordillera to the east of the coastal line (black line). 

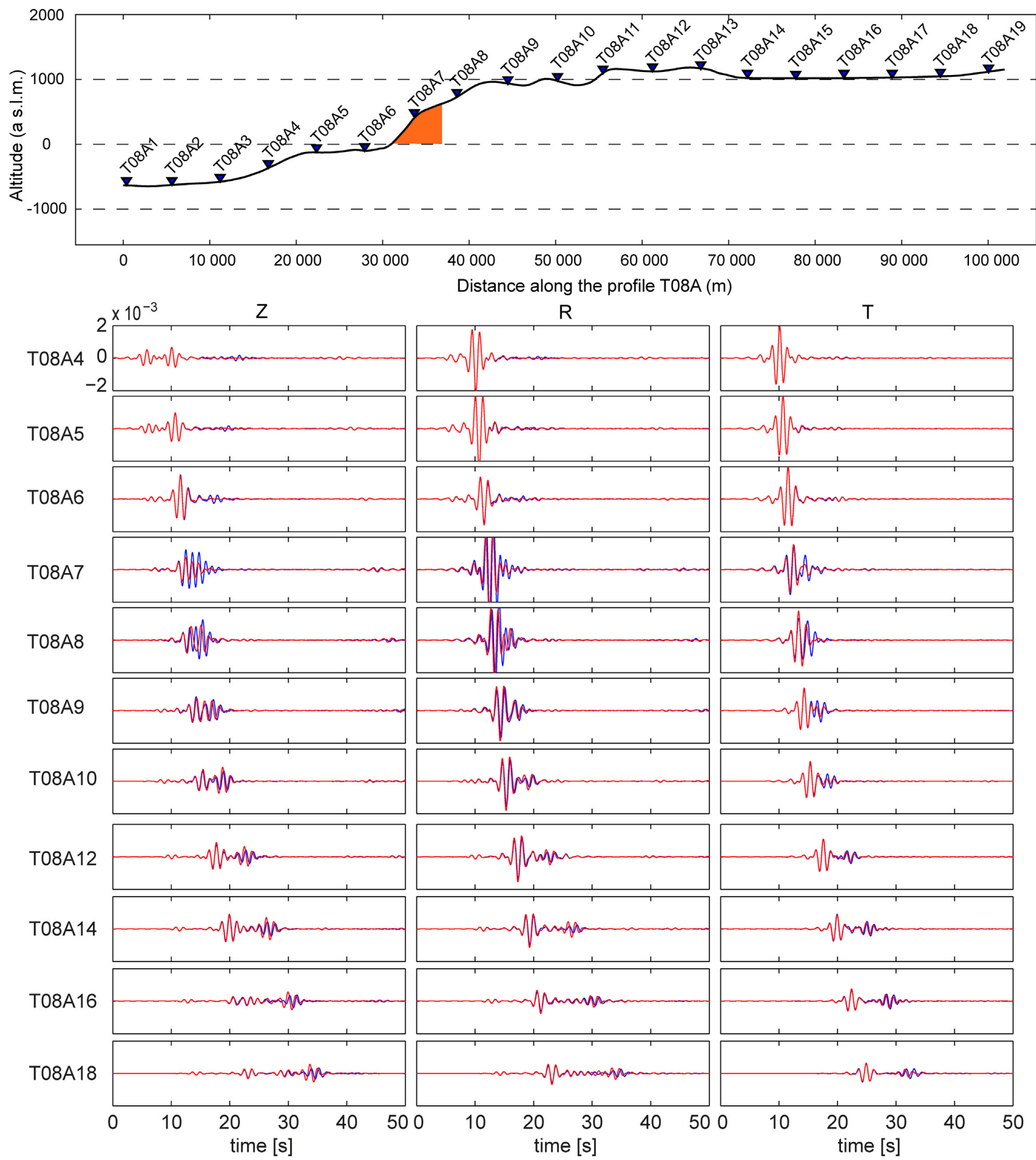

Figure 10. Top: Topography of the T08A profile (Fig. 6), orange polygon represents the modelled Alto Hospicio basin. Bottom: Comparison of synthetic seismograms computed using the 1-D velocity model with topography (red line) and the 1-D velocity model with topography and basins (blue line) for the 2014 July 13 earthquake. The synthetic seismograms are all bandpass filtered between 0.5 and $1.0 \mathrm{~Hz}$. The processed waveforms for the vertical (left), radial (centre) and transverse (right) components are shown for 11 of the 19 stations of the T08A profile (Fig. 6).

of the incident seismic waves and produce reflections on their edges that propagate both within the basin and in the surrounding areas (e.g. Celebi 1987; Frankel et al. 2002; Semblat et al. 2005; Paolucci \& Morstabilini 2006).

In this work, the results show that basin amplifications are strongly frequency-dependent and are related to the size of the basin. For example, in the frequency band between 0.1 and $2.0 \mathrm{~Hz}$
(Fig. 11), amplification occurs in the interior of the basins, reaching amplification ratios of up to 2.9 in the Pampa del Tamarugal basin and 1.8 in the Alto Hospicio basin. The analysis of the amplification in different frequency ranges (Fig. 12) indicates that the amplitude and complexity of the amplification is intimately related to the frequency, as is clearly visible in the increasing amplification values with the increasing frequency bands for the smaller Alto 


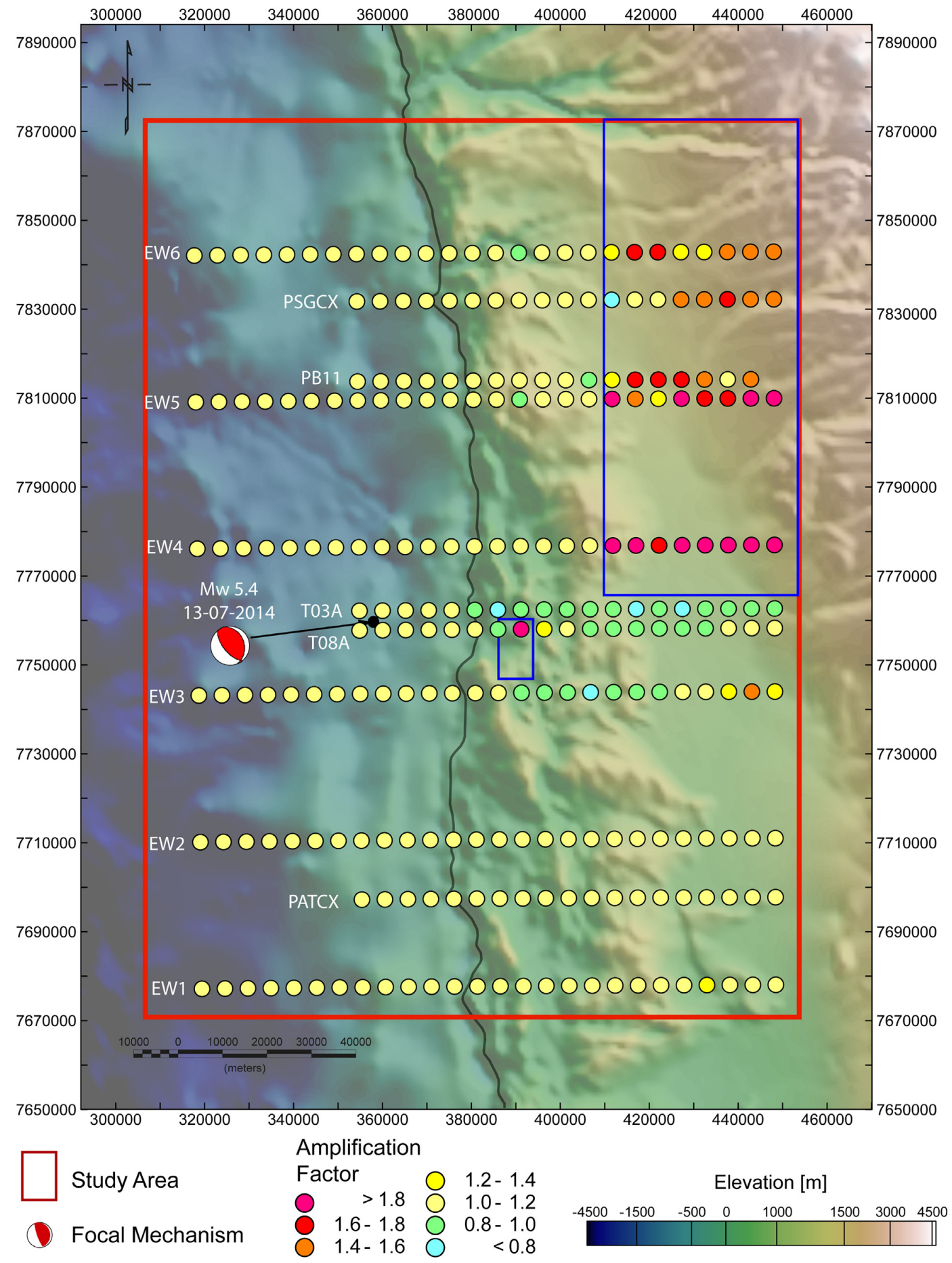

Figure 11. Map showing the energy amplification ratio in the velocity waveforms between synthetic seismograms obtained using the model with topography and the model with topography and basins. The map shows coloured circles for each station location, in which the colours represent the calculated amplification factor with values between $<0.8$ and $>1.8$. Values above 1 represent relative amplification in the topography and basins model, while values below 1 represent relative deamplification. The beach ball represents the $M_{\mathrm{W}} 5.42014$ July 13 earthquake and the blue squares represent the basins. The grey-shaded elevation map shows the geomorphological features related to the coastal cliff and the coastal cordillera to the east of the coastal line (black line).

Hospicio basin. This can be seen as the basin's size interacting more with higher frequency waves (Semblat et al. 2002). These results agree with the results of Paolucci \& Morstabilini (2006), who found that the peak of amplification occurs at frequencies slightly larger than the fundamental resonance frequency of the layer given by $f_{0}=V_{\mathrm{s}} / 4 H$, where $V_{\mathrm{s}}$ is the $S$-wave velocity of the basin and $H$ is the height of the basin. This basin-related amplification frequency dependency was also shown in several previous empirical and analytical studies (Borcherdt 1970; Borcherdt \& Glassmoyer 1992; Field 1996; Semblat et al. 2002; Day et al. 2008)

Ours results also show deamplification occurring at the edges of the basins, probably related to reflected waves that interact with the 

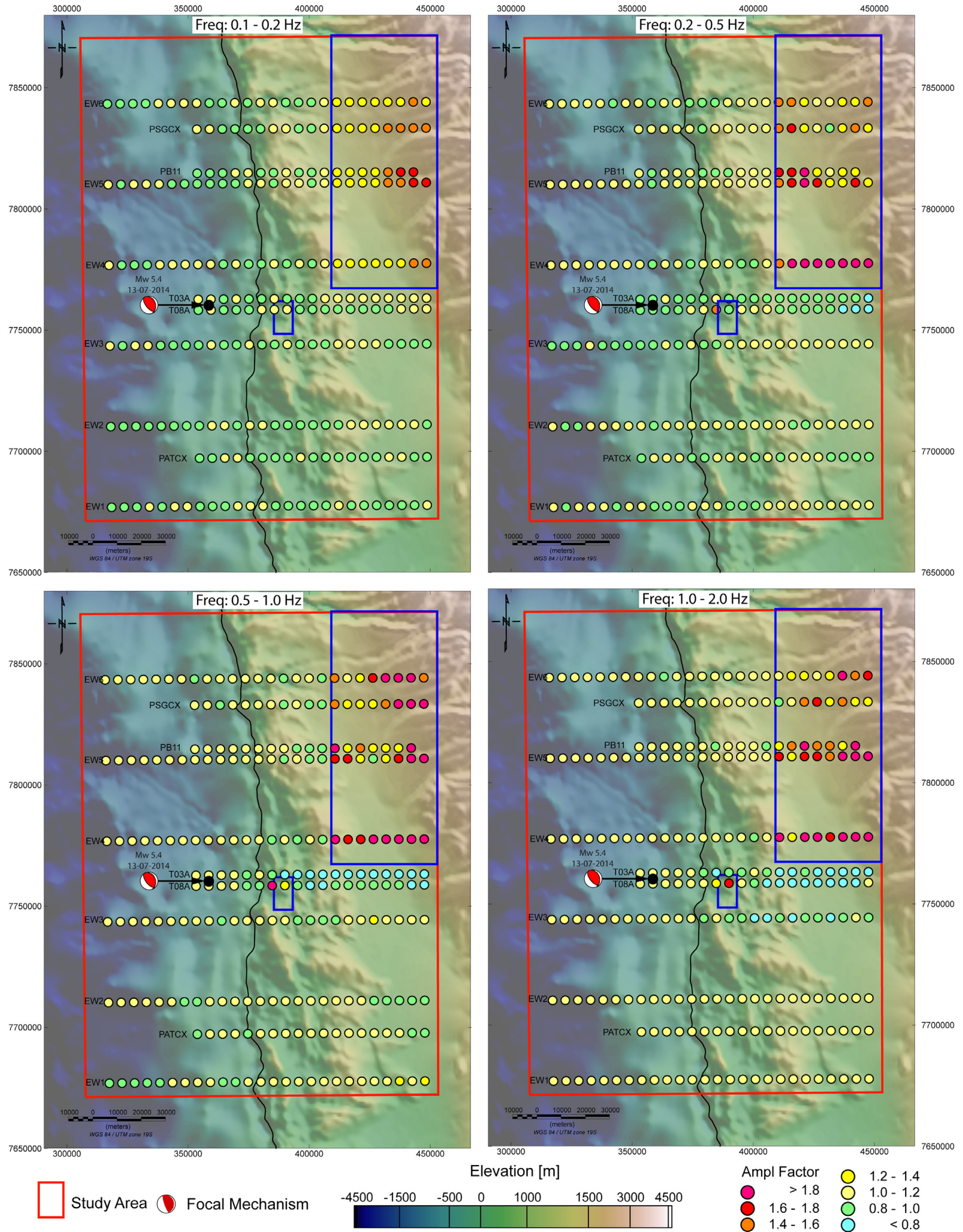

Figure 12. Amplification factor maps for the velocity waveforms between synthetic seismograms obtained using the model with topography and the model with topography and basins for frequency ranges between $0.1-0.2 \mathrm{~Hz}, 0.2-0.5 \mathrm{~Hz}, 0.5-1.0 \mathrm{~Hz}$ and $1.0-2.0 \mathrm{~Hz}$. The maps show coloured circles for each station location, in which the colours represent the calculated amplification factor. Values above 1 represent relative amplification in the topography and basins model, while values below 1 represent relative deamplification. The beach ball represents the $M_{\mathrm{w}} 5.42014$ July 13 earthquake and the blue squares represent the basins. The grey-shaded elevation map shows the geomorphological features related to the coastal cliff and the coastal cordillera to the east of the coastal line (black line). 

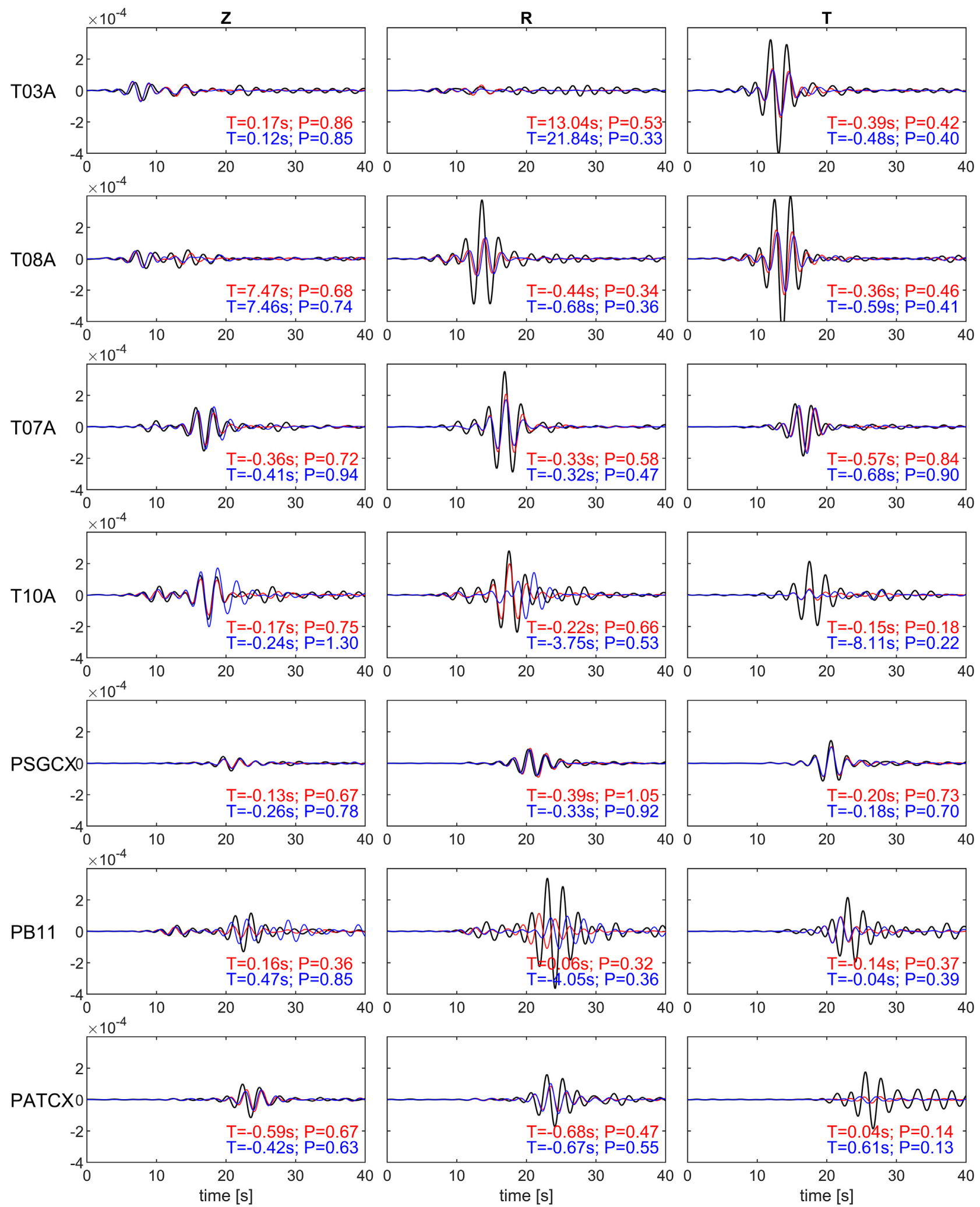

Figure 13. Comparison between the existing good quality real data (black line) for the 2014 April $2 M_{\mathrm{W}} 4.5$ earthquake and synthetic seismograms computed using the 1-D velocity model with topography (red lines), and the 1-D velocity model with topography and basins (blue lines). Synthetic seismograms are double-differentiated to obtain acceleration in $\mathrm{m} \mathrm{s}^{-2}$ and are all bandpass filtered between 0.2 and $0.5 \mathrm{~Hz}$. The processed waveforms for the vertical (left), radial (middle) and transverse (right) components are shown for seven stations ordered by epicentral distance, whose locations are shown in Fig. 6. The phase shift in seconds $(\mathrm{T})$ and the power ratio $(\mathrm{P})$ between the real data and the different model for each station in the three components are also presented, using the same colour code as the lines. 
Z
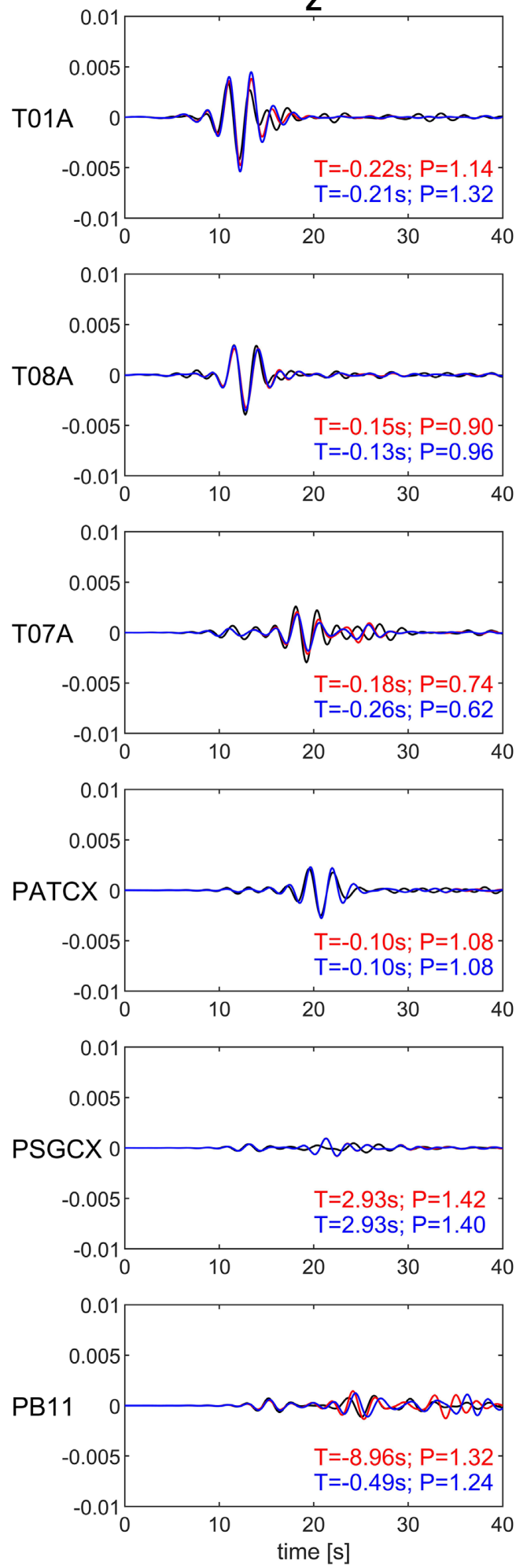

R
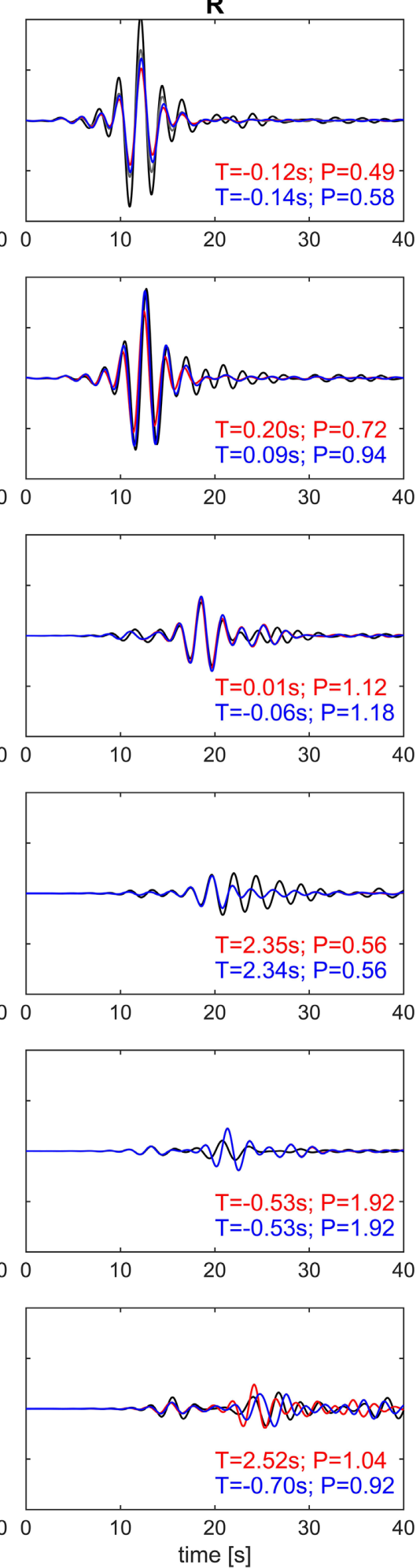
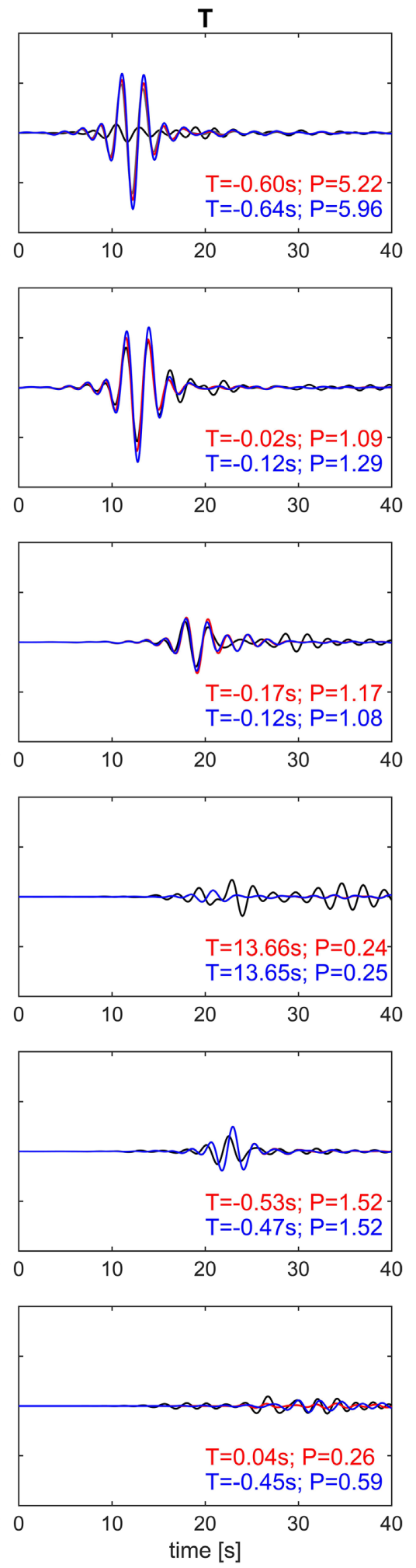

Figure 14. Comparison between the existing good quality real data (black lines) for the 13 July of $2014 M_{\mathrm{w}} 5.4$ earthquake and the synthetic seismograms using the 1-D velocity model with topography (red lines), and the 1-D velocity model with topography and basins (blue lines). Synthetic seismograms are double-differentiated to obtain acceleration in $\mathrm{m} \mathrm{s}^{-2}$ and are all bandpass filtered between 0.2 and $0.5 \mathrm{~Hz}$. The processed waveforms for the vertical (left), radial (middle) and transverse (right) components are shown for six stations ordered by epicentral distance, whose locations are shown in Fig. 6 . The phase shift in seconds $(\mathrm{T})$ and the power ratio $(\mathrm{P})$ between the real data and the different model for each station in the three components are also presented, using the same colour code as the lines. 


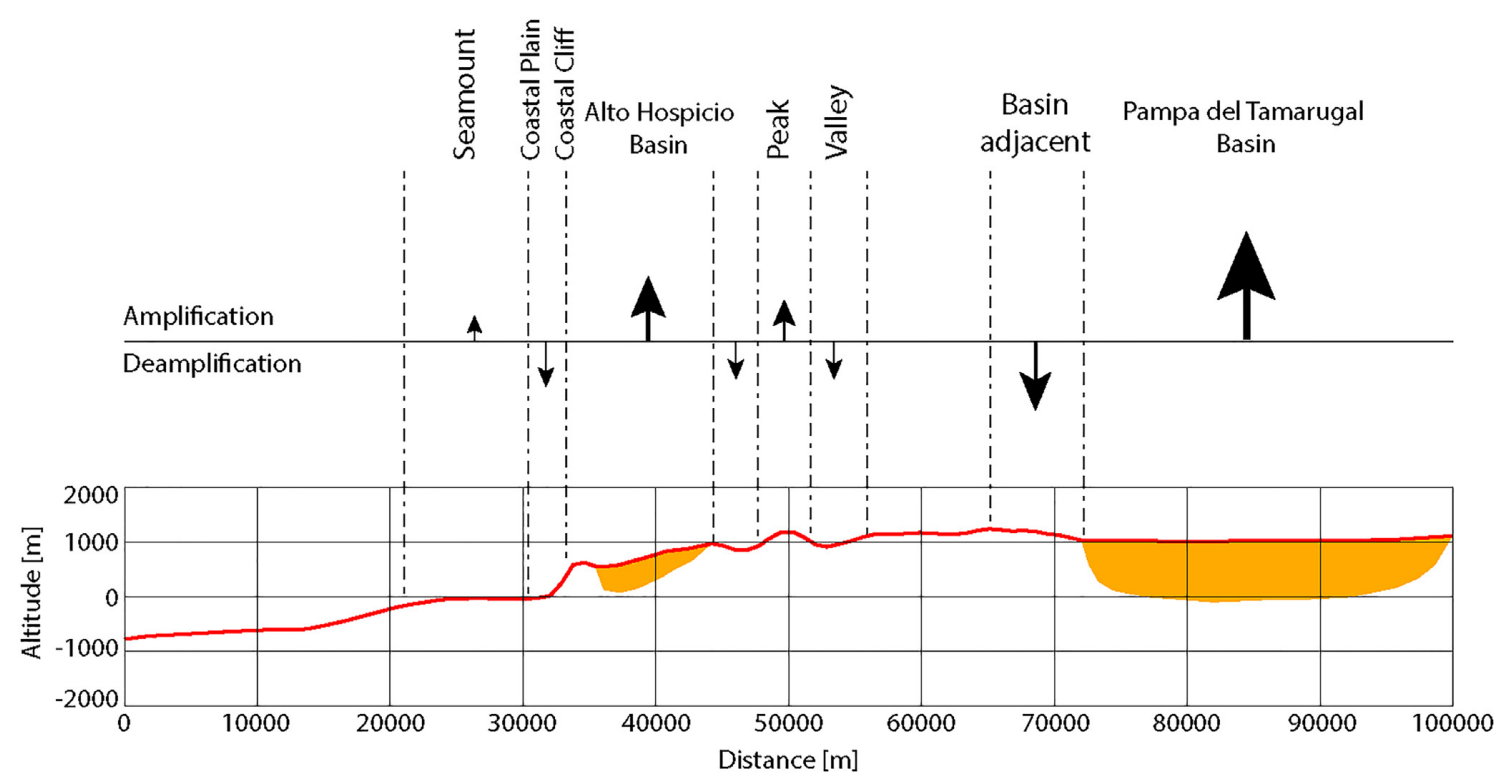

Figure 15. Conceptual model of our study region showing the simulated seismic amplification and de-amplification in the study area and its association with topographic features and basins.

upcoming waves and producing destructive interference. However, the deamplification observed in the southern edge of the basin does have a clear frequency dependence, reaching a minimum value of 0.75 and spatial extent in the frequency range of $0.1-2.0 \mathrm{~Hz}$.

Notwithstanding the simplicity of the basin model used in this study, the amplifications observed in the simulations agree with the results obtained using more complex 3-D velocity basin models in previous studies of other regions. For example, using finitedifference simulations to determine the 3-D seismic response in the Los Angeles basin, Olsen (2000) obtained average amplification factors of up to 4 . We emphasize that the main goal of this study is to obtain a first-order quantification of the effects (e.g. amplification factors) of basins compared to the effect of topography on waveforms in northern Chile. Given the sharp western boundaries of the Alto Hospicio and Pampa del Tamarugal basins, the simple cuboid shapes used to represent them serve this purpose well. Nevertheless, we cannot rule out that some spurious waves may arise from the borders of the basins and that the amplification factors obtained may be model dependent. Future work may focus on higher resolution studies of the effects of the region's basins on seismic wave propagation in smaller subregions of our study region.

\subsection{Comparisons with real data}

Our analyses for the 2014 April $2 M_{\mathrm{w}} 4.5$ and the 2014 July 13 $M_{\mathrm{w}} 5.4$ earthquakes demonstrate that we obtain a good first-order fit between the real waveforms and the modelled waveforms using a simplified 1-D velocity model with topography, notably for wave periods between 2 and $10 \mathrm{~s}(f \sim 0.1-0.5 \mathrm{~Hz})$. A particularly acceptable match between the modelled waveforms and the real data is obtained for stations T01A, T03A, T07A and T08A for both earthquakes (Figs 13 and 14, Supporting Information Figs S15-S22 and S23), with small time-shifts and amplitude differences, especially for the radial and transverse components. The 1-D velocity model with topography and basins shows an acceptable match for the station T08A, which is located in the modelled Alto Hospicio basin, for the 2014 July 13 earthquake, but some differences in amplitude are observed for the 2014 April 2 event. For the station T07A, good match between the simulated waveforms and the real data are observed up to $1.0 \mathrm{~Hz}$, for larger frequencies the fit deteriorates. This may indicate that the station T07A is located in a shallow sedimentary layer, no represented in the model. Poor fits between the real data and the simulated waveforms were obtained for the seismic stations located near or within the Pampa del Tamarugal basin (T10A and PB11, respectively). This disagreement between the real and synthetic waveforms may be related to the simplified geometry and elastic properties of the Pampa del Tamarugal basin that were used in our simulations, which do not consider complex effects related to different soil layers and small-scale heterogeneities in the base of the basin that are essentially unknown.

In the simulations of ground motion in the Los Angeles Basin due to the $M_{\mathrm{w}} 4.2$ Hollywood and Yorba Linda earthquakes performed by Komatitsch et al. (2004), the authors used a spectral element method with 3-D variation of seismic wave speeds, density and topography to constrain a sedimentary basin model based on data from petroleum-industry well logs and seismic reflection profiles. The modelling predicted significant amplification in the basin, and a particularly good match was obtained between the simulated waveforms and the real data at a frequency range up to $0.5 \mathrm{~Hz}$. The different results between our study and those obtained by Komatitsch et al. (2004) can be explained by their detailed representation of the basin geometry and seismic structure, which was only due to the extensive geophysical data available for their study. This confirms that the Pampa del Tamarugal basin model used in this study is too simple and that future and more realistic complex basin models are needed to improve the data fit.

On the other hand, in this study, for frequencies higher than $1 \mathrm{~Hz}$ the fits between the real and simulated waveforms deteriorates for all stations, and the simulations including topography and basins do not capture the complexity of the waveforms. This deterioration may be related to the effects of shallow geological structures that are poorly constrained and hence are not taken into account in our simulations. Additionally, for frequencies lower than $1 \mathrm{~Hz}$, the fit between the real and simulated waveforms also deteriorates with increasing epicentral distance, most notably for the 
2014 July 13 earthquake, whose epicentre was located $20 \mathrm{~km}$ west of the coastal line and which had a depth of $34 \mathrm{~km}$. A good example of this is for station PSGCX, which shows an exceptional fit for the 2014 April 2 earthquake for frequencies between 0.1 and $1.0 \mathrm{~Hz}$ but a poor fit for the 2014 July 13 earthquake (depth = $49 \mathrm{~km}$ ). This highlights the simplicity of the 1-D model used in our study; future studies should focus on the construction of detailed 3-D velocity models of the study region including shallow small-scale heterogeneity. Such high-resolution 3-D velocity models will be crucial for future improved waveform simulations to investigate potential trade-offs between topography and 3-D structure effects.

Although this work analyses just two earthquakes with relatively low magnitudes ( $M_{\mathrm{w}} 4.5$ and 5.4), we observed that amplifications (topography- and basin-related) are larger for the $M_{\mathrm{w}} 5.4$ earthquake. From this very simple observation, we can hypothesize that due to the higher energy of larger earthquakes, seismic amplification due to topography and basins is proportional to earthquakes size. However, with just two examples we cannot establish a quantitative relationship between the amplification factor and earthquake's magnitude.

\subsection{Conceptual model of seismic site effects}

Considering all of the aforementioned analysis, we suggest that the observed damage and seismic amplification in Alto Hospicio city during the 2014 April $1 M_{\mathrm{w}} 8.1$ Iquique earthquake may be related not only to the earthquake's large magnitude but also to the combination of topography and basin effects. However, other effects not considered in this work such as complex shallow fault systems or soil composition and small-scale crustal heterogeneities that are not yet constrained in existing velocity models of the region may also contribute to seismic site effects. Consequently, future work should focus on obtaining detailed seismic images of the fine shallow 3-D velocity structure of the Iquique region, which will be crucial to refining our simulations.

As a summary of the seismic effects due to topography and basins which were simulated in this work, Fig. 15 shows a conceptual model (west-east profile) of the study area, showing the main geomorphological features and their relation with the ground motion amplification or deamplification. Generally, it can be concluded that larger amplifications and deamplifications are related to basins, produced by the reflection of waves in the basin borders and the basin-adjacent areas, respectively. The coastal cliff generates secondary waves that lead to amplification in the coastal cordillera and deamplification in the coastal plains. Within the coastal cordillera, amplification and deamplification effects at frequencies of $1.0-2.0 \mathrm{~Hz}$ are produced by hills and valleys, while the coastal cordillera itself produces amplifications at frequencies of $0.1-0.5 \mathrm{~Hz}$. Amplification corresponding spatially to seamounts, offshore, is also observed in the whole frequency range considered.

Therefore, we suggest that intramountainous basins represent a major seismic hazard for the amplification of ground motion during earthquakes in the Iquique region, due to the combined effects of basins and topography. Accordingly, future work should further assess the intramountainous basins of the coastal cordillera along a distance of more than $1000 \mathrm{~km}$ between Southern Peru and Northern Chile, as they constitute an important risk for future earthquakes in the region.

\section{CONCLUSIONS}

Assessing site effects is not simple. During recent decades, great efforts have been made to evaluate the amplification produced by the local surface geological and geomorphological features during earthquakes. This study showed that relatively simple numerical models are capable of estimating the amplifications generated by local geological conditions to the first order, but the complexity of the interaction between topography and soil materials requires more detailed 3-D velocity models. Despite this, we were able to obtain some general insights into the nature of wave amplification in Northern Chile under different scenarios.

Topographic features in Northern Chile do not significantly modify the incident waveform but rather produce frequency-dependent secondary waves that propagate inland; these waves prolong the duration of the ground motion, and in some sites have larger amplitudes than the incident waves. These secondary waves augment the total energy of the seismic waveforms, producing amplification factors of up to 3.6 (relative to the flat 1-D model) for frequencies between 0.5 and $1.0 \mathrm{~Hz}$.

As has been reported in several previous studies, basins are the geomorphological features that produce the main amplification effects in seismic ground motion, both increasing the amplitudes of the incident seismic waves and generating secondary waves. However, in this work, we highlighted the importance of the interaction between basins and topographic features; for the 1-D model with topography and basins, amplification factors (relative to the topographic 1-D model) of up to 3.9 were observed for frequencies between 1 and $2 \mathrm{~Hz}$.

The conceptual model presented in this work highlights the main amplification effects produced by the interaction between topography and basins in the study area, showing that the Alto Hospicio and Pampa del Tamarugal basins and the coastal cliff are the features that amplified seismic waves the most, and that de-amplification mainly occurs in valleys, the coastal plain and basin-adjacent areas.

Comparisons between real and synthetic seismic waveforms show a good agreement for low frequencies $(0.1-0.5 \mathrm{~Hz})$, but increasingly poorer data fits for higher frequencies. This is likely due to the effects of small-scale, shallow heterogeneities, which are not yet resolved in seismic images of our study region.

We conclude that the interaction between the local basins and topography produces important amplification. Thus, the damage observed in the cities of Iquique and Alto Hospicio during the 2014 April $1 M_{\mathrm{w}} 8.1$ earthquake was likely related to the interaction between the Alto Hospicio basin and the coastal cliff.

\section{ACKNOWLEDGEMENTS}

We sincerely thank Kyle Smith and the anonymous reviewer for their constructive comments on the manuscript that undoubtedly helped to improve this work. In this research we used the ARCHER UK National Supercomputing Service (http://www.archer.ac.uk). We acknowledge the grammar edition of Robin Wylie. This work was funded by Beca Doctorado Nacional Conicyt 21130082 (TGP). This study benefited from fruitful discussions within the TIDES COST Action ES1401. AMGF is grateful for funding from NERC project NE/N011791/1.

\section{DATA AVAILABILITY}

The data underlying this paper will be shared on reasonable request to the corresponding author. 


\section{REFER E N CES}

Aki, K., 1993. Local site effects on weak and strong ground motion, Tectonophysics, 218, 93-111.

Allmendinger, R.W. \& González, G., 2010. Invited review paper: Neogene to Quaternary tectonics of the coastal Cordillera, northern Chile, Tectonophysics, 495(1-2), 93-110.

Álvarez-Rubio, S., Sánchez-Sesma, F.J., Benito, J.J. \& Alarcón, E., 2004. The direct boundary element method: 2D site effects assessment on laterally varying layered media (methodology), Soil Dyn. Earthq. Eng., 24(2), 167-180.

Ashford, S.A., Sitar, N., Lysmer, J. \& Deng, N., 1997. Topographic effects on the seismic response of steep slopes, Bull. seism. Soc. Am., 87(3), 701-709.

Barani, S., Massa, M., Lovati, S. \& Spallarossa, D., 2014. Effects of surface topography on ground shaking prediction: implications for seismic hazard analysis and recommendations for seismic design, Geophys. J. Int., 197(3), 1551-1565.

Barrientos, S., 2018. The seismic network of Chile, Seismol. Res. Lett., 89(2A), 467-474.

Bascuñán, S., Arriagada, C., Le Roux, J. \& Deckart, K., 2016. Unraveling the Peruvian Phase of the Central Andes: stratigraphy, sedimentology and geochronology of the Salar de Atacama Basin $\left(22^{\circ} 30-23^{\circ} \mathrm{S}\right)$, northern Chile, Basin Res., 28(3), 365-392.

Becerra, A., Podestá, L., Monetta, R., Sáez, E., Leyton, F. \& Yañez, G., 2015. Seismic microzoning of Arica and Iquique, Chile, Nat. Hazards, 79(1), 567-586.

Becerra, A., Sáez, E., Podest, L. \& Leyton, F., 2016. The 2014 earthquake in Iquique, Chile: comparison between local soil conditions and observed damage in the cities of Iquique and Alto Hospicio, Earthq. Spectra, 32(3), 1489-1505.

Becker, J.J. 2009. Global Bathymetry and Elevation Data at 30 Arc Seconds Resolution: SRTM30_PLUS Marine Geodesy, 32(4), 355-371, DOI:10.1080/01490410903297766.

Boore, D.M., 1972. A note on the effects of simple topography on seismic SH waves, Bull. seism. Soc. Am., 62(1), 275-284.

Borcherdt, R. \& Glassmoyer, G., 1992. On the characteristics of local geology and their influence on ground motions generated by the Loma Prieta earthquake in the San Francisco Bay region, California, Bull. geol. Soc. Am., 82(2), 603-641.

Borcherdt, R.D., 1970. Effects of local geology on ground motion near San Francisco Bay, Bull. seism. Soc. Am., 60(1), 29-61.

Bouchon, M., 1973. Effect of topography on surface motion, Bull. seism. Soc. Am., 63(2), 615-632.

Bouchon, M., Schultz, C.A. \& Toksoz, M.N., 1996. Effect of threedimensional topography on seismic motion, J. geophys. Res., 101, 58355846.

Bouckovalas, G.D. \& Kouretzis, G.P., 2001. Stiff soil amplification effects in the 7 September 1999 Athens (Greece) earthquake, Soil Dyn. Earthq. Eng., 21(8), 671-687.

Buech, F., Davies, T.R. \& Pettinga, J.R., 2010. The little red hill seismic experimental study: topographic effects on ground motion at a bedrockdominated mountain edifice, Bull. seism. Soc. Am., 100(5A), 2219-2229.

Bürgmann, R., 2014. Earth science: warning signs of the Iquique earthquake, Nature, 512(7514), 258-259.

Burjánek, J., Edwards, B. \& Fäh, D., 2014. Empirical evidence of local seismic effects at sites with pronounced topography: a systematic approach, Geophys. J. Int., 197(1), 608-619.

Campillo, M., Gariel, J.C., Aki, K. \& Sánchez-Sesma, F.J., 1989. Destructive strong ground motion in Mexico City: source, path, and site effects during great 1985 Michoacan earthquake, Bull. seism. Soc. Am., 79(6), 17181735.

Celebi, M., 1987. Topographical and geological amplifications determined from strong-motion and aftershock records of the 3 March 1985 Chile earthquake, Bull. seism. Soc. Am., 77(4), 1147-1167.

Cembrano, J., González, G., Arancibia, G., Ahumada, I., Olivares, V. \& Herrera, V., 2005. Fault zone development and strain partitioning in an extensional strike-slip duplex: a case study from the Mesozoic Atacama fault system, Northern Chile, Tectonophysics, 400(1-4), 105-125.
Cilia, M.G., Mooney, W.D. \& Robinson, A., 2017. A seismic intensity survey of the 1 April 2014 M 8.2 Iquique, Chile, earthquake and tsunami, and a comparison with strong-motion data, Seismol. Res. Lett., 88(5), 12321240.

Comte, D. \& Pardo, M., 1991. Reappraisal of great historical earthquakes in the northern Chile and southern Peru seismic gaps, Nat. Hazards, 4(1), 23-44.

Day, S.M. et al., 2008. Model for basin effects on long-period response spectra in southern California, Earthq. Spectra, 24(1), 257-277.

Dentith, M. \& Mudge, S.T., 2014. Geophysics for the Mineral Exploration Geoscientist, Cambridge Univ. Press.

Dziewonski, A.M., Chou, T-A. \& Woodhouse, J.H., 1981. Determination of earthquake source parameters from waveform data for studies of global and regional seismicity, J. geophys. Res., 86, 2825-2852.

Faccioli, E., 1991. Seismic amplification in the presence of geological and topographic irregularities, in Proceedings of the 2nd International Conference on Recent Advances in Geotechnical Earthquake Engineering and Soil Dynamics, pp. March 11-15, St. Louis, Missouri, Paper No. SOA7. 1779-1797.

Fan, G., Liu, F.C., Wen, R.Z. \& Zhang, J.J., 2014. Research of earthquake topographic effect, Appl. Mech. Mater, 501-504, 1566-1572.

Field, E.H., 1996. Spectral amplification in a sediment-filled valley exhibiting clear basin-edge-induced waves, Bull. seism. Soc. Am., 86(4), 991-1005.

Frankel, A.D., Carver, D.L. \& Williams, R.A., 2002. Nonlinear and linear site response and basin effects in Seattle for the M 6.8 Nisqually, Washington, earthquake, Bull. seism. Soc. Am., 92(6), 2090-2109.

Fuentes, G., Martínez, F. \& Arriagada, C., 2017. Estructura De La Cuenca De Tarapacá En La Pampa Del Tamarugal, Norte De Chile $\left(20^{\circ} 30^{\prime}-21^{\circ} \mathrm{s}\right)$, XX Congreso Geológico Argentino, 7-11 de agosto de 2017 | San Miguel de Tucumán, 104-109.

Galli Olivier, C. \& Dingman, R.J., 1962. Carta Geológica de Chile. Cuadrangulos Pica, Alca, Matilla y Chacarilla con un estudio sobre los recursos de agua subterránea. Provincia de Tarapacá. Escala 1:50.000(Vol. III $\mathrm{N}^{\circ} 2,3,4$ y 5 ).

García-Pérez, T., Marquardt, C., Yáñez, G., Cembrano, J., Gomila, R., Santibañez, I. \& Maringue, J., 2018. Insights on the structural control of a Neogene forearc basin in Northern Chile: a geophysical approach, Tectonophysics, 736(March), 1-14.

Geli, L., Bard, P.Y. \& Jullien, B., 1988. Effect of topography on earthquake ground motion: a review and new results, Bull. seism. Soc. Am., 78(1), $42-63$.

Geosciences \& CNRS-INSU, 2006. IPOC Seismic Network, doi:10.14470/PK615318.

Ghofrani, H., Atkinson, G.M. \& Goda, K., 2013. Implications of the 2011 M9.0 Tohoku Japan earthquake for the treatment of site effects in large earthquakes, Bull. Earthq. Eng., 11(1), 171-203.

González, G., Cembrano, J., Carrizo, D., Macci, A. \& Schneider, H., 2003. The link between forearc tectonics and Pliocene-Quaternary deformation of the Coastal Cordillera, northern Chile, J. South Am. Earth Sci., 16(5), 321-342.

Hayes, G.P. et al., 2017. Tectonic summaries of magnitude 7 and greater earthquakes from 2000 to 2015, U.S. Geological Survey Open-File Report 2016-1192, 148 p., doi:10.3133/ofr20161192.

Hayes, GP. et al., 2014. Continuing megathrust earthquake potential in Chile after the 2014 Iquique earthquake, Nature, 512(7514), 295-298.

Hough, S.E. et al., 2010. Localized damage caused by topographic amplification during the $2010 M_{\mathrm{w}} 7.0$ Haiti earthquake, Nat. Geosci., 3(11), 778-782.

Husen, S., Kissling, E., Flueh, E. \& Asch, G., 1999. Accurate hypocentre determination in the seismogenic zone of the subducting Nazca Plate in northern Chile using a combined on-/offshore network, Geophys. J. Int., 138, 687-701.

Komatitsch, D., Erlebacher, G., Göddeke, D. \& Michéa, D., 2010. High-order finite-element seismic wave propagation modeling with MPI on a large GPU cluster, $J$. Comput. Phys., 229(20), 7692-7714. 
Komatitsch, D., Liu, Q., Tromp, J., Su, P., Stidham, C. \& Shaw, J.H., 2004. Simulations of ground motion in the Los Angeles Basin based upon the spectral-element method, Bull. seism. Soc. Am., 94(1), 187-206.

Komatitsch, D. \& Tromp, J., 1999. Introduction to the spectral element method for three-dimensional seismic wave propagation, Geophys. J. Int., 139, 806-822.

Komatitsch, D. \& Vilotte, J.P., 1998. The spectral element method : an efficient tool to simulate the seismic response of $2 \mathrm{D}$ and $3 \mathrm{D}$ geological structures, Bull. seism. Soc. Am., 88(2), 368-392.

Kuo, C.H., Wen, K.L., Lin, C.M., Hsiao, N.C. \& Chen, D.Y., 2018. Site amplifications and the effect on local magnitude determination at stations of the surface-downhole network in Taiwan, Soil Dyn. Earthq. Eng., 104(September 2017), 106-116.

Lay, T., Yue, H., Brodsky, E.E. \& An, C., 2014. The 1 April 2014 Iquique, Chile, $M_{\mathrm{w}} 8.1$ earthquake rupture sequence, Geophys. Res. Lett., 7(April), $1-8$.

Lee, S.J., Chan, Y.C., Komatitsch, D., Huang, B.S. \& Tromp, J., 2009. Effects of realistic surface topography on seismic ground motion in the Yangminshan region of Taiwan based upon the spectral-element method and LiDAR DTM, Bull. seism. Soc. Am., 99(2A), 681-693.

León-Ríos, S., Ruiz, S., Maksymowicz, A., Leyton, F., Fuenzalida, A. \& Madariaga, R., 2016. Diversity of the 2014 Iquique's foreshocks and aftershocks: clues about the complex rupture process of a $M_{\mathrm{W}} 8.1$ earthquake, J. Seismol., 20(4), 1059-1073.

López, L.A., Cifuentes, J.L., Fuentes, F.C., Neira, H.A., Cervetto, M.M., Troncoso, R.A. \& Feuker, P., 2017. Hidrogeología de la Cuenca de la Pampa del Tamarugal, Región de Tarapacá, Servicio Nacional de Geología y Minería. Carta Geológica de Chile. Serie Hidrogeología, (6), 186 p., 2 mapas a distintas escalas. Santiago.

Magnoni, F., Casarotti, E., Michelini, A., Piersanti, A., Komatitsch, D., Peter, D. \& Tromp, J., 2014. Spectral-element simulations of seismic waves generated by the 2009 L'Aquila earthquake, Bull. seism. Soc. Am., 104(1), 73-94.

Marquardt, C., Lavenu, A., Ortlieb, L., Godoy, E. \& Comte, D., 2004. Coastal neotectonics in Southern Central Andes: uplift and deformation of marine terraces in Northern Chile (27 S), Tectonophysics, 394(3-4), 193-219.

Marquardt, C., Marinovic, N. \& Munoz, V., 2008. Geología de las ciudades de Iquique y Alto Hospicio, Región de Tarapacá, Servicio Nacional de Geología y Minería, Carta Geológica de Chile, Serie Geología Básica, 133: 33p, 1 mapa escala 1:25.000. Santiago.

Martinod, J. et al., 2016. Pleistocene uplift, climate and morphological segmentation of the Northern Chile coasts $\left(24^{\circ} \mathrm{S}-32^{\circ} \mathrm{S}\right)$ : insights from cosmogenic 10Be dating of paleoshorelines, Geomorphology, 274, 7891.

Massa, M., Barani, S. \& Lovati, S., 2014. Overview of topographic effects based on experimental observations: meaning, causes and possible interpretations, Geophys. J. Int., 197(3), 1537-1550.

Massa, M., Lovati, S., D’Alema, E., Ferretti, G. \& Bakavoli, M., 2010. An experimental approach for estimating seismic amplification effects at the top of a ridge, and the implication for ground-motion predictions: the case of Narni, Central Italy, Bull. seism. Soc. Am., 100(6), 3020-3034.

Meza-Fajardo, K.C., Semblat, J.F., Chaillat, S. \& Lenti, L., 2016. Seismicwave amplification in 3D alluvial basins: 3D/1D amplification ratios from fast multipole BEM simulations, Bull. seism. Soc. Am., 106(3), 12671281.

Miksat, J., Wen, K.L., Wenzel, F., Sokolov, V. \& Chen, C.T., 2010. Numerical modelling of ground motion in the Taipei Basin: basin and source effects, Geophys. J. Int., 183(3), 1633-1647.

Molinari, I., Argnani, A., Morelli, A. \& Basini, P., 2015. Development and testing of a 3D seismic velocity model of the Po Plain sedimentary basin, Italy, Bull. seism. Soc. Am., 105(2), 753-764.

Mpodozis, C. \& Ramos, V.A., 2008. Tectónica Jurásica en Argentina y Chile: extensión, Subducción Oblicua, Rifting, Deriva y Colisiones? Revista de la Asociacion Geologica Argentina, 63, 481-497.

Muñoz, N. \& Charrier, R., 1996. Uplift of the western border of the Altiplano on a west-vergent thrust system, Northern Chile, J. South Am. Earth Sci., 9(3-4), 171-181.
Nester, P. \& Jordan, T., 2012. The Pampa del Tamarugal Forearc Basin in Northern Chile: the interaction of tectonics and climate, in Tectonics of Sedimentary Basins: Recent Advances, pp. 369-381, doi:10.1002/9781444347166.ch18.

Olsen, K.B., 2000. Site amplification in the Los Angeles basin from threedimensional modeling of ground motion, Bull. seism. Soc. Am., 90(6 SUPPL.), doi:10.1785/0120000506.

Paolucci, R., 2002. Amplification of earthquake ground motion by steep topographic irregularities, Earthq. Eng. Struct. Dyn., 31(10), 1831-1853.

Paolucci, R. \& Morstabilini, L., 2006. Non-dimensional site amplification functions for basin edge effects on seismic ground motion, in Third International Symposium on the Effects of Surface Geology on Seismic Motion, Grenoble, France, pp. 823-831.

Parisi, L., Ferreira, A.M.G. \& Ritsema, J., 2018. Apparent splitting of $S$ waves propagating through an isotropic lowermost mantle, J. geophys. Res., 123(5), 3909-3922.

Paskoff, R.P., 1978. Sobre la evolución geomorfológica del gran acantilado costero del Norte Grande de Chile, Géogr. Phys. Quat., 32(4), 351.

Pedersen, H.A., Sánchez-Sesma, F.J. \& Campillo, M., 1994. Threedimensional scattering by two-dimensional topographies, Bull. seism. Soc. Am., 84(4), 1169-1183.

Pinto Morales, L., Pastén Puchi, C., Ruiz Tapia, S. \& Leyton Flores, F., 2016. Determinación de Efectos de Sitio en las Estaciones Sismológicas de la Región de Tarapacá, Universidad de Chile, Facultad de Ciencias Fisicas y Matemáticas, Departamento de Ingeniería Civil.

Poursartip, B., Fathi, A. \& Kallivokas, L.F., 2017. Seismic wave amplification by topographic features: a parametric study, Soil Dyn. Earthq. Eng., 92(October 2016), 503-527.

Quezada, J., Cerda, J.L. \& Jensen, A., 2010. Efectos de la tectónica y el clima en la configuración morfológica del relieve costero del norte de Chile, Andean Geol., 37(1), 78-109.

Restrepo, D., Bielak, J., Serrano, R., Gómez, J. \& Jaramillo, J., 2016. Effects of realistic topography on the ground motion of the Colombian Andesa case study at the Aburrá Valley, Antioquia, Geophys. J. Int., 204(3), $1801-1816$

Ruiz, S. et al., 2014. Intense foreshocks and a slow slip event preceded the 2014 Iquique $M_{\mathrm{w}} 8.1$ earthquake, Science, 345(6201), 1165-1169.

Sánchez-Sesma, F.J. \& Campillo, M., 1993. Topographic effects for incident $P, S V$ and Rayleigh waves, Tectonophysics, 218(1-3), 113-125.

Sánchez-Sesma, F.J., Palencia, V.J. \& Luzón, F., 2002. Estimation of local site effects during earthquakes: an overview, ISET J. Earthq. Technol., 39(423), 167-193.

Sánchez-Sesma, F.J., Ramos-Martínez, J. \& Campillo, M., 1993. An indirect boundary element method applied to simulate the seismic response of alluvial valleys for incident P, S and Rayleigh waves, Earthq. Eng. Struct. Dyn., 22(4), 279-295.

Semblat, J.F., Duval, A.M. \& Dangla, P., 2002. Seismic site effects in a deep alluvial basin: numerical analysis by the boundary element method, Comput. Geotech., 29, 573-585.

Semblat, J.F., Kham, M., Parara, E., Bard, P.Y., Pitilakis, K., Makra, K. \& Raptakis, D., 2005. Seismic wave amplification: basin geometry vs soil layering, Soil Dyn. Earthq. Eng., 25(7-10), 529-538.

Sernageomin., 2003. Mapa geologico de chile: version digital, Mapa Geológico de Chile: Versión Digital. Servicio Nacional de Geología y Minería, Publicacio, (CD-ROM, versión 1.0) Santiago. Retrieved from http://geoportal.sernageomin.cl/geovisor/GeoVisor/index.html?resource s=map:ags@http://geoarcgis.sernageomin.cl/ArcGIS/rest/services/geop ortal/GeologiaBase/MapServer

Singh, S.K., Mena, E. \& Castro, R., 1988. Some aspects of source characteristics of the 19 September 1985 Michoacan earthquake and ground motion amplification in and near Mexico City from strong motion data, Bull. seism. Soc. Am., 78(2), 451-477.

Teldford, W.M., Geldart, L.P. \& Sheriff, R.E., 1990. Applied Geophysics, 2nd edn, Cambridge Univ. Press.

Tolorza, V., Marquardt, C. \& Vargas, G., 2009. Sobre la edad del Gran Escarpe Costero, in XII Congreso Geológico Chileno. Santiago, 22-26 Noviembre, p. S10_040. 
Vásquez, P. \& Sepúlveda, F., 2013. Cartas Iquique y Pozo Almonte, Región de Tarapacá. Servicio Nacional de Geologia y Mineria, Carta Geológica de Chile, Serie Geología Básica, Santiago\&nbsp;(1 mapa escala 1:100.000), 162-163.

Veiga, R., Kelley, S., Mpodozis, C., Copeland, P., Jordan, T.E., Pángaro, F. \& Burns, W.M., 2004. Extension and basin formation in the southern Andes caused by increased convergence rate: a mid-Cenozoic trigger for the Andes, Tectonics, 20(3), 308-324.

Viguier, B. et al., 2018. Multidisciplinary study for the assessment of the geometry, boundaries and preferential recharge zones of an overexploited aquifer in the Atacama, J. South Am. Earth Sci., 86, 366-383.

Wang, G., Du, C., Huang, D., Jin, F., Koo, R.C.H. \& Kwan, J.S.H., 2018. Parametric models for 3D topographic amplification of ground motions considering subsurface soils, Soil Dyn. Earthq. Eng., 115, 41-54.

\section{SUPPORTING INFORMATION}

Supplementary data are available at $G J I$ online.

Figure S1. Waveforms comparison for the representative stations T03A, PSGCX and PB11 for coarser (320 elements) and finer (640 elements) meshes for the 2014 April $2 M_{\mathrm{W}} 4.5$ earthquake.

Figure S2. EW cross-section topography profiles comparing the topographies obtained from SPECFEM and from SRTM 90 meter model. See the location of the profiles in Fig. 6.

Figure S3. Comparison of synthetic seismograms computed using the 1-D flat model (black line) and the 1-D model with topography (red line) for the $M_{\mathrm{w}} 5.42014$ July 13. The synthetic seismograms are all bandpass filtered between 0.1 and $0.2 \mathrm{~Hz}$. The processed waveforms for the vertical (left), radial (centre) and transverse (right) components are shown for the 19 stations along the PSGCX profile (Fig. 6).

Figure S4. Comparison of synthetic seismograms computed using the 1-D flat model (black line) and the 1-D model with topography (red line) for the $M_{\mathrm{w}} 5.42014$ July 13 . The synthetic seismograms are all bandpass filtered between 0.2 and $0.5 \mathrm{~Hz}$. The processed waveforms for the vertical (left), radial (centre) and transverse (right) components are shown for the 19 stations along the PSGCX profile (Fig. 6).

Figure S5. Comparison of synthetic seismograms computed using the 1-D flat model (black line) and the 1-D model with topography (red line) for the $M_{\mathrm{w}} 5.42014$ July 13 . The synthetic seismograms are all bandpass filtered between 0.5 and $1.0 \mathrm{~Hz}$. The processed waveforms for the vertical (left), radial (centre) and transverse (right) components are shown for the 19 stations along the PSGCX profile (Fig. 6).

Figure S6. Comparison of synthetic seismograms computed using the 1-D flat model (black line) and the 1-D model with topography (red line) for the $M_{\mathrm{w}} 5.42014$ July 13 . The synthetic seismograms are all bandpass filtered between 1.0 and $2.0 \mathrm{~Hz}$. The processed waveforms for the vertical (left), radial (centre) and transverse (right) components are shown for the 19 stations along the PSGCX profile (Fig. 6).

Figure S7. Comparison of synthetic seismograms computed using the 1-D topography model (red line) and the 1-D topography with basin model (blue line) for the $M_{\mathrm{w}} 5.42014$ July 13 The synthetic seismograms are all bandpass filtered between 0.1 and $0.2 \mathrm{~Hz}$. The processed waveforms for the vertical (left), radial (centre) and transverse (right) components are shown for the 19 stations along the T08A profile (Fig. 6).

Figure S8. Comparison of synthetic seismograms computed using the 1-D topography model (red line) and the 1-D topography with basin model (blue line) for the $M_{\mathrm{w}} 5.42014$ July 13 . The synthetic seismograms are all bandpass filtered between 0.2 and $0.5 \mathrm{~Hz}$. The processed waveforms for the vertical (left), radial (centre) and transverse (right) components are shown for the 19 stations along the T08A profile (Fig. 6).

Figure S9. Comparison of synthetic seismograms computed using the 1-D topography model (red line) and the 1-D topography with basin model (blue line) for the $M_{\mathrm{w}} 5.42014$ July 13 . The synthetic seismograms are all bandpass filtered between 0.5 and $1.0 \mathrm{~Hz}$. The processed waveforms for the vertical (left), radial (centre) and transverse (right) components are shown for the 19 stations along the T08A profile (Fig. 6).

Figure S10. Comparison of synthetic seismograms computed using the 1-D topography model (red line) and the 1-D topography with basin model (blue line) for the $M_{\mathrm{w}} 5.42014$ July 13 . The synthetic seismograms are all bandpass filtered between 1.0 and $2.0 \mathrm{~Hz}$. The processed waveforms for the vertical (left), radial (centre) and transverse (right) components are shown for the 19 stations along the T08A profile (Fig. 6).

Figure S11. Comparison of synthetic seismograms computed using the 1-D topography model (red line) and the 1-D topography with basin model (blue line) for the $M_{\mathrm{w}} 5.42014$ July 13 The synthetic seismograms are all bandpass filtered between 0.1 and $0.2 \mathrm{~Hz}$. The processed waveforms for the vertical (left), radial (centre) and transverse (right) components are shown for the 19 stations along the PB11 profile (Fig. 6).

Figure S12. Comparison of synthetic seismograms computed using the 1-D topography model (red line) and the 1-D topography with basin model (blue line) for the $M_{\mathrm{w}} 5.42014$ July 13 . The synthetic seismograms are all bandpass filtered between 0.2 and $0.5 \mathrm{~Hz}$. The processed waveforms for the vertical (left), radial (centre) and transverse (right) components are shown for the 19 stations along the PB11 profile (Fig. 6).

Figure S13. Comparison of synthetic seismograms computed using the 1-D topography model (red line) and the 1-D topography with basin model (blue line) for the $M_{\mathrm{w}} 5.42014$ July 13 . The synthetic seismograms are all bandpass filtered between 0.5 and $1.0 \mathrm{~Hz}$. The processed waveforms for the vertical (left), radial (centre) and transverse (right) components are shown for the 19 stations along the PB11 profile (Fig. 6).

Figure S14. Comparison of synthetic seismograms computed using the 1-D topography model (red line) and the 1-D topography with basin model (blue line) for the $M_{\mathrm{w}} 5.42014$ July 13 . The synthetic seismograms are all bandpass filtered between 1.0 and $2.0 \mathrm{~Hz}$. The processed waveforms for the vertical (left), radial (centre) and transverse (right) components are shown for the 19 stations along the PB11 profile (Fig. 6).

Figure S15. Comparison of real data (black lines) for the 2014 April $2 M_{\mathrm{w}} 4.5$ earthquake and synthetic seismograms for this earthquake computed using the 1-D model with topography (blue lines) and 1-D model with topography and basins (red lines). Synthetic seismograms are double differentiated to obtain acceleration (in $\mathrm{m} \mathrm{s}^{-2}$ ) and are all bandpass filtered between 0.1 and $0.2 \mathrm{~Hz}$. The processed waveforms for the vertical (left), radial (middle) and transverse (right) components are shown for seven stations ordered by epicentral distance, whose locations are shown in Fig. 6. The phase shift in seconds $(\mathrm{T})$ and the power ratio $(\mathrm{P})$ between the real data and the different model for each station in the three components is also presented, using the same colour code as the lines.

Figure S16. Comparison of real data (black lines) for the 2014 April $2 M_{\mathrm{w}} 4.5$ earthquake and synthetic seismograms for this earthquake computed using the 1-D model with topography (blue lines) and 
1-D model with topography and basins (red lines). Synthetic seismograms are double differentiated to obtain acceleration (in $\mathrm{m} \mathrm{s}^{-2}$ ) and are all bandpass filtered between 0.2 and $0.5 \mathrm{~Hz}$. The processed waveforms for the vertical (left), radial (middle) and transverse (right) components are shown for seven stations ordered by epicentral distance, whose locations are shown in Fig. 6. The phase shift in seconds $(\mathrm{T})$ and the power ratio $(\mathrm{P})$ between the real data and the different model for each station in the three components is also presented, using the same colour code as the lines.

Figure S17. Comparison of real data (black lines) for the 2014 April $2 M_{\mathrm{w}} 4.5$ earthquake and synthetic seismograms for this earthquake computed using the 1-D model with topography (blue lines) and 1-D model with topography and basins (red lines). Synthetic seismograms are double differentiated to obtain acceleration (in $\mathrm{m} \mathrm{s}^{-2}$ ) and are all bandpass filtered between 0.5 and $1.0 \mathrm{~Hz}$. The processed waveforms for the vertical (left), radial (middle) and transverse (right) components are shown for seven stations, ordered by epicentral distance, whose locations are shown in Fig. 6. The phase shift in seconds $(\mathrm{T})$ and the power ratio $(\mathrm{P})$ between the real data and the different model for each station in the three components is also presented, using the same colour code as the lines.

Figure S18. Comparison of real data (black lines) for the 2014 April $2 M_{\mathrm{w}} 4.5$ earthquake and synthetic seismograms for this earthquake computed using the 1-D model with topography (blue traces) and 1-D model with topography and basins (red lines). Synthetic seismograms are double differentiated to obtain acceleration (in $\mathrm{m} \mathrm{s}^{-2}$ ) and are all bandpass filtered between 1.0 and $2.0 \mathrm{~Hz}$. The processed waveforms for the vertical (left), radial (middle) and transverse (right) components are shown for six stations, whose locations are shown in Fig. 6. The phase shift in seconds (T) and the power ratio (P) between the real data and the different model for each station in the three components is also presented, using the same colour code as the lines.

Figure S19. Comparison of real data (black lines) for the 2014 July $13 M_{\mathrm{w}} 5.4$ earthquake and synthetic seismograms for this earthquake computed using the 1-D model with topography (blue lines) and 1-D model with topography and basins (red lines). Synthetic seismograms are double differentiated to obtain acceleration (in $\mathrm{m} \mathrm{s}^{-2}$ ) and are all bandpass filtered between 0.1 and $0.2 \mathrm{~Hz}$. The processed waveforms for the vertical (left), radial (middle) and transverse (right) components are shown for six stations, whose locations are shown in Fig. 6 . The phase shift in seconds $(\mathrm{T})$ and the power ratio $(\mathrm{P})$ between the real data and the different model for each station in the three components is also presented, using the same colour code as the lines.
Figure S20. Comparison of real data (black lines) for the 2014 July $13 M_{\mathrm{w}} 5.4$ earthquake and synthetic seismograms for this earthquake computed using the 1-D model with topography (blue lines) and 1-D model with topography and basins (red lines). Synthetic seismograms are double differentiated to obtain acceleration (in $\mathrm{m} \mathrm{s}^{-2}$ ) and are all bandpass filtered between 0.2 and $0.5 \mathrm{~Hz}$. The processed waveforms for the vertical (left), radial (middle) and transverse (right) components are shown for six stations, whose locations are shown in Fig. 6. The phase shift in seconds $(\mathrm{T})$ and the power ratio $(\mathrm{P})$ between the real data and the different model for each station in the three components is also presented, using the same colour code as the lines.

Figure S21. Comparison of real data (black lines) for the 2014 July $13 M_{\mathrm{w}} 5.4$ earthquake and synthetic seismograms for this earthquake computed using the 1-D model with topography (blue lines) and 1-D model with topography and basins (red lines). Synthetic seismograms are double differentiated to obtain acceleration (in $\mathrm{m} \mathrm{s}^{-2}$ ) and are all bandpass filtered between 0.5 and $1.0 \mathrm{~Hz}$. The processed waveforms for the vertical (left), radial (middle) and transverse (right) components are shown for six stations, whose locations are shown in Fig. 6. The phase shift in seconds (T) and the power ratio $(\mathrm{P})$ between the real data and the different model for each station in the three components is also presented, using the same colour code as the lines.

Figure S22. Comparison of real data (black lines) for the 2014 July $13 M_{\mathrm{w}} 5.4$ earthquake and synthetic seismograms for this earthquake computed using the 1-D model with topography (blue lines) and 1-D model with topography and basins (red lines). Synthetic seismograms are double differentiated to obtain acceleration (in $\mathrm{m} \mathrm{s}^{-2}$ ) and are all bandpass filtered between 1.0 and $2.0 \mathrm{~Hz}$. The processed waveforms for the vertical (left), radial (middle) and transverse (right) components are shown for six stations, whose locations are shown in Fig. 6. The phase shift in seconds $(\mathrm{T})$ and the power ratio $(\mathrm{P})$ between the real data and the different model for each station in the three components is also presented, using the same colour code as the lines.

Figure S23. cross-correlations phase misfit and amplitude ratio plots. The symbols show the misfits between the real data and 1D topography model (red) and 1-D topography and basin model (blue) for each component (circles for vertical, squares for radial and diamond for transversal) plotted as source distance from left to right for the four frequency ranges used in this study.

Please note: Oxford University Press are not responsible for the content or functionality of any supporting materials supplied by the authors. Any queries (other than missing material) should be directed to the corresponding author for the paper. 